\title{
An Update on the Assessment and Management of Pediatric Abdominal Pain
}

\author{
Craig Friesen \\ Jennifer M Colombo \\ Amanda Deacy \\ Jennifer $V$ Schurman \\ Division of Gastroenterology, \\ Hepatology, and Nutrition; Children's \\ Mercy Kansas City, Kansas City, \\ MO, USA
}

\begin{abstract}
Chronic abdominal pain is very common in children and adolescent and results in high personal and social costs. Most youth with chronic abdominal pain fulfill criteria for a functional abdominal pain disorder (FAPD) as defined by Rome criteria. These are complex conditions with a wide array of biological, psychological, and social factors contributing to the experience of pain. The purpose of the current review is to provide an overview of the pathophysiology of FAPDs and an up-to-date summary of the literature related to FAPDs in children and adolescents, with additional focus on several areas (eg, diet and probiotics) where patients and families frequently have questions or implement self-directed care. We also provide an approach to the assessment and treatment of pediatric FAPDs focusing on the robust literature regarding psychological interventions and much sparser literature regarding medication treatment.
\end{abstract}

Keywords: abdominal pain, functional abdominal pain disorders, functional dyspepsia, irritable bowel syndrome, biopsychosocial model

\section{Introduction}

Chronic abdominal pain is very common in children and adolescent and results in high personal and social costs. ${ }^{1}$ It is associated with reduced health-related quality of life (QOL) comparable to organic gastrointestinal diseases. ${ }^{2}$ The worldwide prevalence has been estimated at $13.5 \%$ with comparable rates across continents. ${ }^{3}$ It is more common in females with a peak prevalence in the early teens. ${ }^{3}$

Most youth with chronic abdominal pain fulfill criteria for a functional gastrointestinal disorder (FGID) as defined by Rome criteria. ${ }^{4}$ Within the relatively broader category of FGIDs, there are four recognized functional abdominal pain disorders (FAPDs) including irritable bowel syndrome (IBS), functional dyspepsia (FD), abdominal migraine, and functional abdominal pain syndrome, with IBS and FD being the two most common. ${ }^{5,6}$ (See Table 1 for criteria) Criteria for FGIDs in pediatrics were first adopted by expert consensus in 1999 (Rome II). ${ }^{7}$ They were revised in 2006 (Rome III) and again in 2016 (Rome IV). ${ }^{4,7}$ They have remained largely consensus-based, having never been fully validated or shown to predict treatment response. Particularly, for IBS and FD, transition to Rome IV brought significant changes resulting in different prevalence estimates and creating doubt on whether existing research utilizing Rome III criteria can be extrapolated to patients currently defined by Rome IV. ${ }^{8}$ Lastly, there are additional challenges in that the criteria are inconsistently applied, and diagnoses differ in comparing parent- and patient-reported symptoms. ${ }^{9,10}$ Despite these challenges, there is value in the
Correspondence: Craig Friesen

Tel $+|-8| 6-302-3065$

Fax + I-816-302-9735

Email cfriesen@cmh.edu 
Table I Rome IV Criteria for Functional Abdominal Pain Disorders in Children and Adolescents

Functional Dyspepsia*:
I. Postprandial fullness
2. Early satiation
3. Epigastric pain or burning not associated with defecation

Irritable Bowel Syndrome*:

I. Abdominal pain in association with at least one of the following:

- Related to defecation

- A change in stool frequency

- A change in stool form

2. In children with constipation, the pain must not resolve with resolution of the constipation

Abdominal Migraine: at least 2 episodes of all of the following, fulfilled for at least 6 months:

Paroxysmal episodes of intense, acute periumbilical, midline or diffuse abdominal pain lasting at least I hour

I. Episodes separated by weeks to months

2. Pain is incapacitating and interferes with normal activities

3. Stereotypical pattern and symptoms in the individual patient

4. Pain is associated with 2 or more of the following:

- Anorexia

- Nausea

- Vomiting

- Headache

- Photophobia

- Pallor

Functional Abdominal Pain*:

I. Episodic or continuous abdominal pain that does not occur during physiologic events (eg eating, menses)

2. Insufficient criteria for irritable bowel syndrome, functional dyspepsia or abdominal migraine

Notes: *Must occur at least 4 times per month for 2 months. For all: After appropriate evaluation, the abdominal pain cannot be fully explained by another medical condition. Data from Hyams et al. ${ }^{4}$

clinician being familiar with the criteria as they represent the classification used in nearly all treatment trials. In addition, it has been demonstrated that providing the patient with a positive diagnosis may enhance treatment outcomes. ${ }^{11}$

While FAPDs are precisely defined, it should be recognized that patients can fulfill criteria for more than one FAPD. There are a significant number of youths with chronic abdominal pain who fulfill criteria for both IBS and FD, and overlap has significantly increased with institution of Rome IV criteria. ${ }^{12}$ Further, overlap of FAPDs with other health issues is common. Specifically, youth with FD have been shown to have high rates of both gastroesophageal reflux and overactive bladder symptoms. ${ }^{13}$ Additionally, there can be significant symptom heterogeneity within a specific diagnosis. Nausea, which occurs in high proportions of patients with either FD or IBS, may be of particular importance. Nausea has been associated with worse abdominal pain and gastrointestinal symptoms, somatic symptoms, sleep disturbances, depression, anxiety, disability, poor school and social functioning, school absences, and poorer QOL. ${ }^{14-17}$ Nausea also predicts a higher rate of persistence of gastrointestinal and somatic symptoms, anxiety, and depression into adulthood. ${ }^{14}$ As such, nausea may be an important treatment target in FAPDs.

The purpose of the current review is to provide an upto-date summary of the literature related to FAPDs in children and adolescents, with additional focus on several areas (eg, diet and probiotics) where patients and families frequently have questions or implement self-directed care. We also provide an approach to the assessment and treatment of pediatric FAPDs focusing on the robust literature regarding psychological interventions and much sparser literature regarding medication treatment.

\section{Biopsychosocial Model}

It has become abundantly clear that the development of chronic abdominal pain is a complex process. The biopsychosocial model has long-been recognized within the context of chronic abdominal pain and recognizes that symptoms arise through numerous pathways that include biologic factors (eg, genetics, dysmotility, visceral hypersensitivity, inflammation, sleep disturbances, dysbiosis), psychologic factors (eg, anxiety, depression, dysfunctional coping), and social factors (eg, poor relationships with parents, peers, or teachers) which interact with each other. All these factors can contribute to the initiation or maintenance of pain as well as the severity and frequency of on-going symptoms, and all have been reported in FAPDs. Although the model remains relevant, it continues to evolve recognizing a much greater complexity within FAPD pathophysiology. Biologic factors can now be broken down into three main systems- neurologic, immunologic, and endocrinologic- which all communicate readily with each other and the psychologic system. Likely, other factors in the initial biopsychosocial model also are comprised of influential and interacting systems. Improved understanding of these will increase the complexity of screening and evaluation, but also provide more tailored treatment options given the somewhat unique combination of contributors believed to underlie each patient's presentation. 
While a discussion of all known factors and their interactions are beyond the scope of this paper, it is useful to provide some examples of how factors interact (Figure 1). There appear to be four main interacting systems which readily communicate with each other: psychologic, neurologic, immunologic, and endocrinologic. Most known pain triggers interact with one or more of these systems starting a cascade resulting in the experience of abdominal pain. Visceral hyperalgesia, an exaggerated response to a potentially painful occurrence (such as bowel distension) is believed to be one of the central mechanisms in FAPDs. Sensitivity to stretch has been shown in youth with recurrent abdominal pain and, specifically, in IBS. ${ }^{18-20}$ In adults, infusion of acid into the stomach or duodenum can result in pain and infusion of acid or lipid into the duodenum can increase gastric sensitivity to distension, providing one mechanism by which diet may induce pain. ${ }^{21-26}$ Diet will be discussed more later. FAPDs are associated with aberrant motility although it has been difficult to link dysmotility to specific symptoms or symptom severity. ${ }^{27}$ Also within this biologic realm, there is mounting evidence implicating inflammation in FAPDs, particularly mast cells in IBS and both mast cells and eosinophils in FD. ${ }^{28-30}$ An important mechanism by which stress can trigger symptoms is through activation of mucosal mast cells, which in turn,
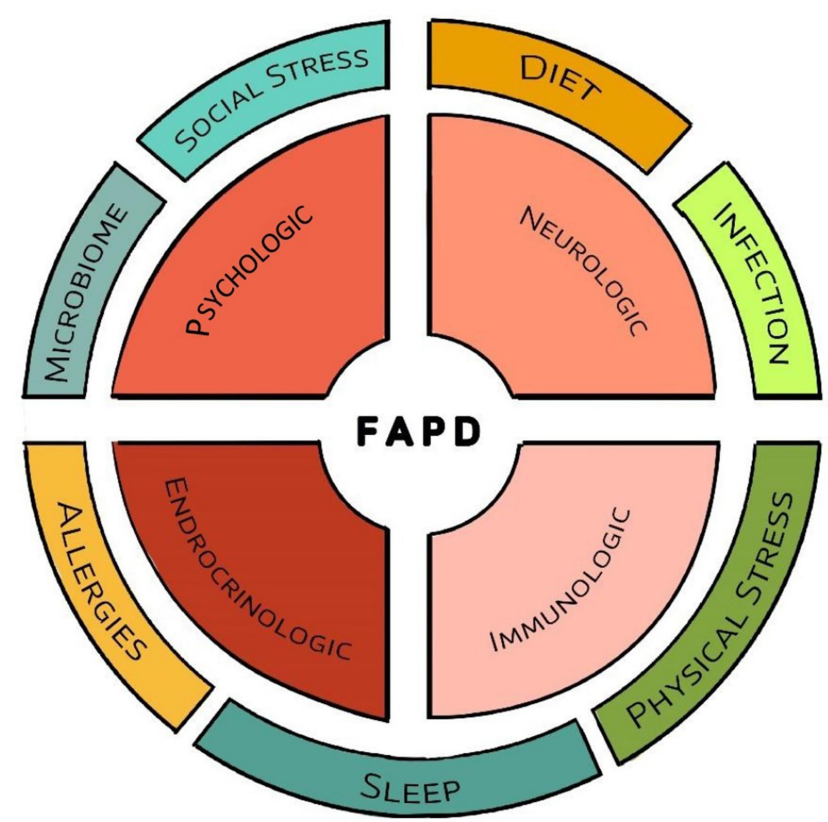

Figure I Overview of factors involved in the pathophysiology of functional abdominal pain disorders. Central to this process are four interacting systems with a variety of factors which interact with these systems and in some instances, with each other. release mediators transmitting a pain message, or which sensitize nerves resulting in hyperalgesia. ${ }^{31,32}$ There is an association between mucosal mast cells and/or eosinophils with anxiety and depression in youth with FD and IBS. $^{33,34}$

There is also increasing recognition of an altered intestinal microbiome and an interrupted intestinal barrier having a role in FAPD pathogenesis. Although there is great variability regarding the specific bacteria altered, IBS, in particular, is associated with an altered microbiome composition and possibly more importantly, an altered milieu of bacterial metabolic products. ${ }^{35,36}$ Bacteria can directly affect visceral sensation and alter expression of tight junction proteins allowing increased passage of antigens, prompting an immunologic reaction. ${ }^{37}$ Likewise, the intestinal barrier can also be disrupted by stress and inflammation. ${ }^{38}$ Barrier dysfunction has been reported in $37-62 \%$ of adults with diarrhea-predominant IBS (IBS-D) and $4-25 \%$ of those with constipation-predominant IBS (IBS-C). ${ }^{39}$ All four pediatric studies assessing the intestinal barrier in patients with IBS have demonstrated barrier dysfunction, which is associated with abdominal pain, symptom severity, depression, and anxiety. ${ }^{39}$

Psychologic disturbances frequently co-exist and interact with biologic factors, cutting across FAPD diagnoses, and are associated with abdominal pain severity. ${ }^{40}$ Pediatric FAPDs are associated with increased anxiety and depression, both of which are associated with increased abdominal pain severity and disability. ${ }^{40,41}$ The presence of psychologic dysfunction predicts worse outcomes and persistence into adulthood. ${ }^{41,42}$ In addition, coping style can significantly affect symptom severity and outcomes. ${ }^{40,41}$ While anxiety and depression appear to be triggers for abdominal pain, it also appears that abdominal pain is a trigger for anxiety and depression. ${ }^{43}$

Lastly, considerable evidence now implicates sleep disturbances (SD) in FAPDs which are associated with more severe gastrointestinal symptoms, more emotional disturbances, hyperalgesia, and upregulation of inflammatory cytokines. ${ }^{44-50}$ Difficulties related to sleep onset and maintenance, the most common SD followed by excess somnolence, are equally distributed across FAPDs, more common in adolescents, and associated with increased functional disability. ${ }^{47}$ In children and adolescents, the total sleep hours and the number of night awakenings predict the prevalence of pain the following day. ${ }^{48}$ Additionally, sleep disturbance is associated with worse clinical outcomes in youth with FAPDs. ${ }^{42}$ 
Table 2 Alarm Signs and Symptoms for Youth with Chronic Abdominal Pain with Suggested Initial Evaluation

\begin{tabular}{|c|c|}
\hline Alarm Sign or Symptom & Evaluation \\
\hline $\begin{array}{l}\text { Weight loss } \\
\text { Deceleration of growth } \\
\text { Delayed Puberty }\end{array}$ & $\begin{array}{l}\text { Complete blood count, C-reactive protein, stool calprotectin (or lactoferrin), and celiac } \\
\text { serology }\end{array}$ \\
\hline $\begin{array}{l}\text { Excessive vomiting } \\
\text { Right upper quadrant pain }\end{array}$ & Liver function tests, amylase, lipase, urinalysis, and abdominal ultrasound \\
\hline $\begin{array}{l}\text { Hematemesis or hematochezia } \\
\text { Right lower quadrant pain } \\
\text { Severe chronic diarrhea } \\
\text { Perianal disease } \\
\text { Systemic symptoms such as unexplained fever or } \\
\text { arthritis } \\
\text { Family history of inflammatory bowel disease or } \\
\text { celiac disease }\end{array}$ & $\begin{array}{l}\text { Complete blood count, C-reactive protein, stool calprotectin (or lactoferrin), celiac } \\
\text { serology, and endoscopy }\end{array}$ \\
\hline Dysphagia & Barium swallow and endoscopy \\
\hline
\end{tabular}

While the previous description of the biopsychosocial model and FAPD pathophysiology represents only a very small portion of the literature, we hope it gives a sense of the complexity of FAPDs. More importantly, the goal is to give a useful working knowledge of the model as patient and family education on the construct represents a vital first step in treatment and has a positive effect on treatment outcomes. ${ }^{51}$ What patients and their family understand about FAPDs, their complex physiology, and treatment has a significant impact on engagement, adherence, and outcomes. ${ }^{52}$ This model forms the basis for seeking to identify the multiple factors operating in any given patient and the rationale for recommendations targeting biologic and psychologic processes.

\section{Evaluation}

As previously stated, most children and adolescents with chronic abdominal pain will fulfill criteria for a FAPD. The great majority will not have a specific "organic" disease or will have findings (particularly on endoscopy) which are of unknown clinical significance. ${ }^{53}$ FAPDs are intended to be positive diagnoses based on symptom profiles that do not require a work-up to rule out other conditions to establish the diagnosis. However, Rome criteria contain the caveat that they are diagnosed "after appropriate evaluation" which is largely undefined. ${ }^{4}$ No evidence-based guidelines exist to direct evaluation and there is wide variability in testing performed across pediatric gastroenterologists. ${ }^{9}$
It is common practice to search for "red flag" or alarm symptoms and to use non-invasive laboratory testing to identify patients needing additional evaluation before diagnosing an FAPD, and in the absence of these alarm symptoms, to make a diagnosis of an FAPD without testing. Alarm symptoms are symptoms that generally are infrequent in FAPD or at least, indicative of greater severity. Table 2 contains signs and symptoms which have been utilized as alarm symptoms to indicate a potential need for further testing. While these are utilized in practice, there is limited evidence supporting their validity. Differentiating IBS from inflammatory bowel disease (IBD) is of particular importance when evaluating youth with chronic abdominal pain. Fortunately, literature is strongest in this area. Specifically, alarm symptoms of hematochezia and weight loss (or problems gaining weight) have been shown to be helpful in differentiating Crohn's disease from FAPDs. ${ }^{54}$ Selecting patients for further evaluation for IBD also may be aided by laboratory assessment. The presence of anemia increases the likelihood of IBD. ${ }^{54}$ Serum C-reactive protein (CRP) and stool calprotectin or stool lactoferrin also have utility in indicating IBD including in children and adolescents. ${ }^{55-60}$ However, results must be interpreted with caution. While a low calprotectin decreases the chances of IBD (particularly in combination with a low CRP), it does not eliminate IBD from the diagnosis; similarly an elevated calprotectin does not necessarily indicate IBD, particularly in patients with diarrhea-predominant IBS. ${ }^{55,58,61}$ While most studies do not support a relationship between celiac disease and pediatric 
FAPDs, one Italian study found a 4-fold increase in celiac (4.4\% vs $1 \%$ ) in youth with IBS and another study found a borderline increase. ${ }^{62,63}$ Both the American Gastroenterological Association (AGA) and the pediatric Rome committee have recommended celiac screening in IBS. ${ }^{4,64}$ Evidence for screening laboratory evaluations in FAPDs other than IBS are limited.

Special mention should be made of the role of endoscopy as it is costly and somewhat controversial in terms of its necessity and value in the context of FAPDs. Endoscopy is generally performed to identify pathology or conversely to rule-out an organic disease to establish the diagnosis of an FAPD. The diagnostic yield of esophagogastroduodenoscopy (EGD) has been widely studied, with histologic inflammation (esophagitis, gastritis, duodenitis) and/or the presence of Helicobacter pylori being present in $23-93 \%$ of patients. $^{53}$ While the disease prevalence appears high, the clinical significance of these findings is not well-established. The role of endoscopy may be shifting from a "search for disease" to a "search for biologic contributors" within the biopsychosocial model, particularly the presence of eosinophils and mast cells. Although there are not well-established criteria for histologically defining eosinophilic gastroenteritis, and norms have not been established for mucosal mast cell densities, both have been extensively studied. Eosinophils and mast cells have been implicated in FD, while mast cells have been implicated in IBS pathogenesis. $^{28-30}$

Current evidence, albeit limited, and recommendations support minimal initial diagnostic testing in youth with suspected FAPDs. Therapeutic interventions are the initial approach with diagnostic testing reserved for patients with alarm symptoms. Further evaluation should also be considered for patients not responding to treatment, searching not only for less common diseases (eg, cholelithiasis or renal anomalies with ultrasound) but potentially also for biological contributors (eg, mast cells and eosinophils with endoscopy).

\section{Treatment \\ Diet}

There has been a great interest in the role of diet in patients with FAPDs. Over $90 \%$ of youth with FAPDs identify at least one food that they associate with worsening of gastrointestinal symptoms. ${ }^{65,66}$ As compared to healthy controls, youth with FAPDs avoid foods more frequently and more often implement diet strategies. ${ }^{65,66}$
While adverse food reactions could be related to allergies, malabsorption, or anticipation of symptoms, there has also been an interest in the effects of specific dietary components interacting with components of the brain-gut axis.

\section{FODMAPS}

Fermentable oligosaccharides, disaccharides, monosaccharides, and polyols (FODMAPs) are common dietary components which have been implicated in FAPDs, particularly IBS. The low FODMAP diet is presumed to result in a decrease in gas production and subsequently a decrease in distension with a decrease in pain. The diet also results in improved barrier function and decreased inflammation. ${ }^{67,68} \mathrm{~A}$ systematic review of the low FODMAP diet in functional abdominal pain concluded that the diet may be effective in adults but that more data was needed to assess its efficacy in pediatrics. ${ }^{69}$ Long-term effectiveness of a low FODMAP diet has been reported in $57 \%$ of adults with IBS. ${ }^{70}$ As in adults, there is a subset of pediatric FAPD patients who demonstrate increased pain with fructan (a FODMAP) ingestion. ${ }^{66,71,72}$ In a cross-over trial in children with IBS, Chumpitazi and colleagues demonstrated that fructans increased pain frequency and the severity of bloating and flatulence with increased production of hydrogen gas. ${ }^{72}$ A double-blind cross-over trial comparing the low FODMAP diet to the "the typical American childhood diet" found decreased abdominal pain with the low FODMAP diet. ${ }^{73}$ Efficacy of the diet appears to be related to the baseline microbial composition. $^{73-75}$ Although short-term studies suggests efficacy, studies assessing whether a low FODMAP diet results in long-term benefit are needed in children. The diet places a high burden on the patient and family and has potential for adverse effects including decreased fiber and calcium intake, as well as a decrease in potentially beneficial bacteria. ${ }^{76}$ A small adult study suggests that this latter effect can be overcome by supplementation with Bifidobacteria-containing probiotics but more studies are needed, particularly in children. ${ }^{77}$

Particularly in IBS, as recommended by AGA IBS guidelines, an empiric trial of a low FODMAP diet appears to be a reasonable initial intervention although not yet a strong recommendation in children and adolescents. The low FODMAP diet is instituted in 3 phases: restriction, reintroduction, and personalization. ${ }^{78}$ If initial restriction is beneficial, eliminated foods are reintroduced sequentially to determine specific foods associated with symptoms followed by personalization where only the 
specific symptom-causing foods are eliminated. The resulting diet should be evaluated by a dietician to ensure adequate intake of fiber, vitamins, and both macro- and micronutrients.

\section{Gluten}

In pediatrics, the only clear entity where gluten has a documented adverse effect is celiac disease, where gluten induces an immunologic reaction. While one study found an increased prevalence of celiac disease in pediatric IBS and another found a borderline association, most studies have not supported an association between celiac disease and FAPDs in children. ${ }^{62,63} \mathrm{~A}$ few studies, mostly in adults, suggest that a gluten-containing diet may induce symptoms in some patients with IBS. ${ }^{79}$ In adults, 7-15\% of the population report that wheat induces gastrointestinal symptoms but only 1 of 6 are confirmed with a doubleblind wheat challenge. ${ }^{80}$ Randomized controlled trials to assess the effects of gluten have produced mixed results. ${ }^{81}$ In adults with refractory FD, 35\% responded to a glutenfree diet but only $18 \%$ of these recurred on a double-blind challenge. $^{82}$ Pediatric data is sparse. In a study of 1114 children with chronic gastrointestinal symptoms, only $3.3 \%$ exhibited symptoms correlated with wheat ingestion. $^{83}$ Of these, $39 \%$ were positive on a doubleblind gluten challenge. ${ }^{83}$

The mechanisms by which gluten and/or wheat may induce symptoms is not well understood. Gluten/wheat can induce inflammation, increase mast cell density, and alter the microbiome as seen in FD and IBS. ${ }^{84-86}$ It is also possible, and even likely, that symptoms are induced by other components of wheat such as FODMAPs. ${ }^{79,87}$ When adults reporting non-celiac gluten sensitivity were given diets with fructans, gluten, or placebo, only fructans induced symptoms. ${ }^{88}$

While gluten or other components of wheat may contribute to symptoms in some patients, gluten restriction should not be viewed as routine management and should only be undertaken after celiac serologic testing. Like other restrictive diets, if the patient deems the diet to be beneficial and decides to remain on it, a dietician should be consulted to ensure the nutritional adequacy of the restricted diet.

\section{Disaccharides/Sugars}

Disaccharidase deficiencies appear to be common in youth with FAPDs. [El-Chammas; Chumpitazi; Colombo] However, the clinical significance of deficiencies is not well established. These deficiencies are not associated with specific symptoms or symptom severity. ${ }^{89-91}$ This should not be surprising as there are several factors involved in symptom generation including the degree of deficiency, the amount of sugar consumed, microbiome composition, intestinal motility, and psychosocial functioning. ${ }^{92}$ If diarrhea is present, the Rome working group recommends a 710-day trial of restriction of lactose, fructose, and poorly absorbed sugars such as sorbitol. Three sugars have drawn particular attention: fructose, lactose, and sucrose.

Fructose is a common dietary sugar present in fruits, fruit juices, some vegetables, honey, table sugar, and obviously, high fructose corn syrup. Fructose malabsorption is common in children with FAPDs but has been demonstrated in a higher percentage of healthy controls. $^{93}$ It has been demonstrated that clinical symptoms correlate with symptoms experienced during a fructose breath test, but not with measures of malabsorption. ${ }^{94}$ Fructose restriction has been shown to be helpful in a subset of children with FAPDs. ${ }^{94-97}$

Seventy percent of the population develop very low lactase levels. ${ }^{90}$ Although lactase deficiency is common in pediatric FAPDs, symptoms experienced during a lactose malabsorption test are more specific for lactose intolerance than are measures of malabsorption. ${ }^{98}$ In most but not all studies, lactose restriction does not lead to relief of symptoms even in patients with demonstrated malabsorption. ${ }^{92,99-101}$ The effects of lactose malabsorption may be more complex and persist after restriction as lactose malabsorption is associated with increased colonic lymphocytes, eosinophils, and mast cells as well as visceral hypersensitivity, which may represent secondary therapeutic targets if symptoms persist after lactose elimination. ${ }^{102-105}$

There has been recent interest in a possible role for sucrase deficiency in FAPDs. The sucrase-isomaltase enzyme accounts for virtually all sucrase and isomaltase activity as well as $80 \%$ of maltase activity indicating an important role in starch digestion as well as sucrose digestion. ${ }^{106}$ Sucrase deficiency, whether measured by mucosal assay or sucrose breath test, is common in pediatric FAPDs. ${ }^{89,90,107}$ Sucrase deficiency is not predicted by any specific symptom or symptom complex. ${ }^{91,107}$ Hypomorphic SI gene variants as seen in congenital sucrase-isomaltase deficiency (CSID) are increased in IBS and predict non-response to a low FODMAP diet. $^{108,109}$ In adults with IBS, a sucrose and starch restricted diet resulted in significant improvement in both gastrointestinal and non-gastrointestinal symptoms. ${ }^{110,111}$ 
As recommended by the Rome committee, empiric restriction of fructose, lactose, and poorly absorbed sugars such as sorbitol is a reasonable early step in managing IBS. A trial of sucrose and starch restriction is also reasonable. There is no need to undertake tests of malabsorption as they are not predictive of response.

\section{Lipids}

Increased small intestinal lipid sensitivity has been demonstrated in adults with both FD and IBS. ${ }^{112,113}$ Two-thirds of FD patients demonstrate sensitivity. ${ }^{114}$ Duodenal lipids lead to fullness, bloating, and nausea, and enhance sensitivity to distension. ${ }^{114}$ In adults with FAPD, high fat meals induce greater pain, nausea, and sensitivity than do high carbohydrate meals. ${ }^{113,115}$ When unblinded, cognitive perceptions of fat can alter symptoms and brain activity following lipid intake. ${ }^{116}$ Whether dietary restriction of fat is useful is largely unknown, but care should be taken to not overly restrict fats particularly in growing, developing children.

\section{Spicy Foods}

In adults with IBS, higher consumption of spicy foods is associated with more symptoms. ${ }^{117}$ In an adult population, frequent consumption of spicy foods was associated with an increased prevalence of IBS but only in women. ${ }^{118}$ In adults with IBS as compared to healthy controls, spicy meals significantly increased abdominal pain and burning, while oral burning was similar. ${ }^{119}$

Most studies have evaluated the effects of capsaicin, a component of red pepper which stimulates TRPV1. Oral capsaicin increases symptoms in approximately 50\% of adults with FD and symptoms in this group increase more than in patients with IBS or healthy controls. ${ }^{120-123}$ In adults with IBS, rectal capsaicin application results in a dose-dependent increase in urge and pain perception. ${ }^{124}$ Increased pain perception was most evident in those with visceral hyperalgesia and was associated with anxiety. ${ }^{124}$

It is reasonable for patients to self-evaluate reactions to spicy foods as the symptoms should occur rapidly, and then only restrict if spicy foods exacerbate symptoms.

\section{Fiber}

Studies evaluating fiber as a treatment for FAPDs have largely been confined to evaluation of fiber supplements and not increasing dietary fiber. Benefits are probably most related to water retention stimulating peristalsis and slow fermentation to produce short-chain fatty acids which in turn, preserve the intestinal barrier, promote antiinflammatory actions, inhibit mast cell activation, and may decrease visceral sensitivity. ${ }^{125-127}$ A meta-analysis of adult studies found that soluble fiber improved symptoms and abdominal pain scores, while there was no evidence for efficacy of insoluble fiber. ${ }^{128}$ Adult IBS clinical guidelines recommend a trial of soluble fiber, but not insoluble fibers such as bran. ${ }^{64,129}$

There have been five controlled studies of fiber in pediatric FAPDs. ${ }^{130}$ One involved treatment with corn fiber which is insoluble and resulted in a decrease in pain attacks. ${ }^{131}$ The other four studies utilized various soluble fibers. No benefit was shown for glucomannan or ispaghula husk. ${ }^{132,133}$ Psyllium has been shown to decrease pain episodes without altering breath hydrogen or methane production, intestinal permeability, or microbiome composition. ${ }^{134}$ Partially hydrolyzed guar gum was shown to improve bowel habits, but improvement in abdominal pain did not reach statistical significance. ${ }^{135}$

Supplementation with soluble fibers is a reasonable early intervention in IBS. Whether increasing dietary fiber, which is often a combination of both soluble and insoluble fiber, is helpful is not known with the exception that bran appears to have little treatment value.

\section{Food Allergies}

There is a well-established association between IBS and atopic conditions. $^{136,137}$ The association of IBS with mucosal mast cells and FD with mucosal mast cells and eosinophils might also suggest a possibility of allergeninduced inflammation. ${ }^{28-30}$ There is not conclusive data implicating IgE-mediated reactions to food as identified by skin prick testing. ${ }^{137,138}$ Based on studies utilizing colonoscopic allergen provocation test (COLAP), it appears that patients may have local allergic reactions within the mucosa without systemic symptoms and which are not identified by skin prick testing or food-specific IgE testing. ${ }^{139-141}$ These findings cast doubt on the ability of standard allergy testing to provide a list of safe foods based on negative results. Aguiler-Lizarraga have proposed that these localized reactions may represent part of a spectrum of reactions with systemic reactions to foods at one end of the spectrum. ${ }^{139}$

There may also be a role for environmental allergens. Indeed, environmental pollen exposure has been shown to have as strong or stronger influence on pain occurrence in youth with FAPDs than does negative affect or hours of sleep. ${ }^{48}$ Birch allergy has been particularly studied. In 
adults with birch allergy, during birch allergy season, mucosal eosinophils and mast cells are increased compared to out-of-season and frequently associated with oral allergy syndrome with birch-associated foods. ${ }^{142,143}$ Cecal COLAP utilizing Bet $\mathrm{v}-1$, the active allergen in birch pollen which cross-reacts with foods, demonstrated an association between positive reactions and a history of pollinosis and reactions to birch-associated foods but no correlation with skin prick testing. ${ }^{140}$

Although controversial, there are some studies implicating IgG or more specifically, IgG4-mediated food reactions. IgG and IgG4 food reactions are generally increased in IBS patients as compared to healthy controls. ${ }^{144-146}$ These may represent food exposures in patients with impaired barriers as opposed to immunologic reactions contributing to symptoms, as resolution of food allergies is generally associated with development of increased food-specific $\operatorname{IgG}$ and IgG4 levels. ${ }^{147,148}$ On the contrary, several studies have shown improvement in symptoms on elimination diets based on food-specific IgG testing with a prompt decrease in food-specific IgG in one study. ${ }^{145,149,150}$

In the absence of a systemic allergic reaction or oral allergy syndrome, routine allergy testing is not recommended in the absence of a clear relationship between a food and symptoms. It should be remembered that the reaction may be local to the mucosa and not identified by standard skin prick tests or food-specific IgE. There may be value in testing for cross-reacting foods or empirically eliminating cross-reacting foods when allergies to specific pollens are identified.

\section{Diet Conclusion}

Although there are no interventional studies evaluating a healthy diet, there is no reason not to recommend a normal, healthy diet in patients with FAPDs. ${ }^{79}$ Recommending good hydration, eating regularly and slowly, limiting excessive fat intake, and watching for symptom exacerbations with spicy foods or any specific foods also seems to make common sense given the current state of the literature. ${ }^{151}$ If a food appears to exacerbate symptoms, it should not be assumed that the reason is known (eg, allergy, gluten content), especially if that leads to other excessive restrictions, as foods have many components that could potentially increase pain. In patients with IBS, an empiric trial of a low FODMAP diet (as recommended in AGA guidelines) or of fructose, lactose, and poorly absorbed sugars (as recommended by the Rome committee) are reasonable but should be followed by reintroduction and personalization. If a restricted diet is used for long-term management, consultation with a dietician would be appropriate to ensure nutritional adequacy of the diet.

\section{Probiotics}

Probiotics are living microorganisms which provide health benefits when consumed. Probiotics are used to alter the microbiome composition and/or metabolic activity modulating inflammation and permeability, and possibly altering susceptibility to food allergy. ${ }^{38,137,152}$ To our knowledge, there have been 13 randomized trials of probiotics in youth with FAPDs. ${ }^{153-165}$ Benefit has been demonstrated in at least some patient groups in eleven of these studies. Benefit has been demonstrated in 4 of 6 studies utilizing Lactobacillus reuteri, 5 of 6 studies utilizing Lactobacillus $G G$, and in 3 studies utilizing Bifidobacteria species, Bifidobacteria and Lactobacillus species, or a combination of Bacillus coagulase and a prebiotic, respectively. ${ }^{153-165}$ Benefit has occurred most commonly in patients with IBS, to a lesser degree in FAP, and less often in FD. Benefit is most often reflected by improvement, but not resolution, in pain frequency and/or intensity. Studies comparing probiotics are lacking as are studies identifying reliable predictors of response. Despite this lack of data, probiotics are a reasonable early intervention in IBS.

\section{Psychologic Treatment}

Although an association between abdominal pain and psychologic dysfunction does not mean cause-andeffect in either direction, once present, psychologic dysfunction likely contributes to symptoms and thus becomes an important therapeutic target. A significant proportion of children with FAPDs have clinically relevant anxiety or depression. ${ }^{166}$ In addition, one study found that $35-45 \%$ of children with FAPDs have subclinical elevations in anxiety. ${ }^{167}$ This latter group presents some challenges as they would likely benefit from psychological intervention but do not have a diagnosable psychologic condition. Psychologic features impact clinical outcomes and are associated with increased symptom severity and disability. ${ }^{41}$ In addition to the broad categories of anxiety and depression, response to treatment is influenced by response to several pain-specific targets including catastrophizing, parent-perceived disease threat, and avoidance behaviors. ${ }^{41,168,169}$ 
Aligning psychologic and medical care allows more comprehensive treatment of the patient but requires regular communication. ${ }^{170}$ In addition, educating the patient and family on the biopsychosocial model and incorporating psychologic care at the beginning decreases resistance to behavioral healthcare. ${ }^{170,171}$ Lastly, simply instructing the patients and families to find a therapist is unlikely to be an adequate approach. ${ }^{170}$ An AGA expert review defined best practices to include the medical provider knowing the features of the most common psychologic interventions and establishing a relationship involving direct referral and ongoing communication with 1-2 mental health providers while continuing to be involved in the on-going care team. ${ }^{172}$ Below, we discuss some of the more common and most supported psychologic interventions including cognitive behavioral therapy, hypnotherapy, biofeedback-assisted relaxation training, and mindfulness-based treatment.

\section{Cognitive Behavioral Therapy}

Cognitive behavioral therapy (CBT) is a short-term psychotherapy which aims to alter maladaptive thoughts, coping, and behaviors that contribute to symptom escalation or maintenance. ${ }^{170,173}$ Patients are taught to recognize and challenge distorted thoughts, engage in positive coping, and change behaviors to promote well-being. ${ }^{173}$ CBT also employs exposure-based exercises in which patients face sensations or situations that cause fear in order to gradually alleviate stress and decrease symptoms while improving quality of life. ${ }^{170,173} \mathrm{CBT}$ for children with FAPDs and their parents has been shown to decrease pain and severity of gastrointestinal symptoms while improving parental responses and decreasing solicitous behaviors. ${ }^{170,174}$ Compared to a variety of controls including standard medical care, CBT has been shown to be effective in decreasing symptoms and increasing functioning in most, but not all, studies with demonstrated longterm benefit. ${ }^{174-180}$ To improve access, CBT delivered by phone or internet has been evaluated in a substantial number of studies with findings very similar to in-person CBT. ${ }^{181-187}$ Phone/internet CBT has been shown to decrease pain, activity limitations, catastrophizing, parental solicitousness, functional disability, missed school days, GI-specific anxiety, and avoidance behaviors while improving QOL. ${ }^{181,183,185-187}$

\section{Hypnotherapy}

Hypnotherapy is a form of medical hypnosis where posthypnotic suggestions focus on abdominal discomfort to relax automatic reactions to symptoms and increase a feeling of self-efficacy in dealing with symptoms. It usually involves weekly sessions (6-12) led by a therapist with daily practice using audio recordings with guided imagery. ${ }^{170,173}$ Hypnotherapy and guided imagery have been shown to decrease pain scores, pain-related disability, and missed activities with long-term benefit. ${ }^{188-}$ ${ }^{190}$ As with CBT, home-based audio-recorded guided imagery has been shown to be effective. ${ }^{191,192}$ Overall, these therapies have resulted in success rates (pain reduction or resolution) in $50-85 \%{ }^{188,189,191-193}$

\section{Biofeedback-Assisted Relaxation Training}

Biofeedback is a technique where individuals are trained to relieve ${ }^{170,173}$ physical and emotional symptoms utilizing physiologic data displayed visually or aurally. ${ }^{194}$ When combined with relaxation training, it is termed biofeedback-assisted relaxation training (BART). BART addresses physiologic contributors to symptoms, providing concrete methods to cope with pain and stress, blunting the physical stress response and enhancing self-efficacy over pain. ${ }^{170,194}$ BART generally requires 4-6 sessions. BART has been shown to be effective in children with FD and duodenal eosinophilia. ${ }^{194}$ As compared to medications alone, medications combined with BART resulted in more rapid improvement in pain frequency and intensity. ${ }^{194}$ In children with recurrent abdominal pain, biofeedback combined with fiber was shown to be superior to fiber alone and adding CBT or parental support did not enhance this effect. ${ }^{195}$

\section{Mindfulness}

Mindfulness utilizes meditation and non-judgmental awareness of the current moment without any attempt to change the current situation. ${ }^{170,173}$ It requires training and practice. Mindfulness training has been shown to reduce stress and anxiety in adults and children and depression in adults. ${ }^{170,196,197}$ Mindfulness-based treatment has been demonstrated to improve symptoms and quality-of-life (QOL) in adults with IBS, at least in part, by decreasing reactivity to gut-focused anxiety and catastrophizing with refocused attention. ${ }^{198-200}$ There are no published studies of mindfulness-based treatment in youth with FAPDs.

\section{Psychologic Treatment Conclusion}

Psychologic therapies are vitally important in the treatment of children with FAPDs, addressing the numerous psychologic co-morbidities, decreasing disability, and increasing QOL. These interventions are also clearly 
helpful in decreasing pain frequency and/or severity; however, pain is often only partially relieved, and patients will need additional interventions to fully resolve pain. Although CBT has the most empiric support, there are other interventions, particularly hypnotherapy, that are useful, and which may resonate better with individual patients. The goal should be to "fill the toolbox" of the patient and care-givers with a variety of positive coping skills to deal with pain, enhancing self-efficacy, and decreasing school and activity avoidance, in particular.

\section{Placebo}

Both the placebo effect and spontaneous improvement are significant contributors to the therapeutic response to a medication. ${ }^{201}$ The placebo effect is subject to a wide variety of influences including the consistency of symptoms, dosing frequency, duration of treatment and the patient-provider relationship. ${ }^{201-203}$ The placebo response rate has varied in adult FD trials (6-72\%) and adult IBS trials (3-84\%) with an overall response rate of $45 \% .{ }^{204}$ In a systematic review and meta-analysis of pediatric FAPD trials, the overall placebo response rate was $41 \%{ }^{202}$

Placebo may even be effective when the patient is aware that they are taking a placebo, likely dependent on the language utilized to introduce the placebo. In a trial of an open-label placebo versus no treatment in adults with IBS, the placebo resulted in increased global improvement, decreased symptom severity, and an increase in adequate relief. ${ }^{205}$ In another study of adults with IBS, response to an open-label placebo was superior to no treatment and not significantly different from the response to a blinded placebo. ${ }^{206}$ The response to placebo seems to support the idea that if a patient believes an intervention is likely to be helpful, this may have psychological benefits in reducing the impact of stress or promoting positive coping. Additionally, these findings underline the importance of placebo-controlled trials in this patient group.

\section{Medications}

Currently, regarding medications, it may not be possible to treat pediatric FAPDs in an evidence-based fashion. First, Rome II and Rome III FAPD diagnostic criteria form the basis for entry into most published studies and not only have these criteria evolved significant differences under Rome IV, but evidence suggests that these diagnoses are not assigned in a consistent fashion across clinicians. ${ }^{10}$ Second, there is a relative paucity of pediatric placebocontrolled medication trials, often utilizing medications at doses below those that are used clinically. Third, FAPDs are complex conditions with widely varying contributors across the patient population which are not controlled for in most therapeutic trials. ${ }^{207}$ Most currently prescribed medications have only a single published trial to support their use and when there is more than one trial, results may be conflicting.

While there are many medications used in clinical practice (particularly in adults), we will largely focus on placebo-controlled trials in youth with FAPDs. ${ }^{208,209}$ To our knowledge, there have been 15 randomized placebocontrolled trials of medications for pediatric FAPDs. ${ }^{158,210-223}$ We have summarized these studies in Table 3. The current data does not lend itself to the development of pediatric practice guidelines regarding medication treatment for pediatric FAPDs as have been developed for adult IBS. ${ }^{64}$ Given the lack of high quality, replicated data, we offer treatment recommendations based on current pediatric literature, adult practice guidelines, and common usage among pediatric gastroenterologists who themselves are quite variable in how they utilize medications to treat this patient population. ${ }^{9}$

\section{Functional Dyspepsia}

It is common practice to treat patients with FD initially with acid-reduction therapy, which has the most literature support, albeit still meager. ${ }^{9,215,224}$ Another medication to consider is cyproheptadine, which is supported by oneplacebo controlled trial and 2 retrospective studies. ${ }^{214,225,226}$ Cyproheptadine is an antagonist of specific serotonin receptors, histamine-1 receptors and muscarinic receptors which may be effective, at least in part, through improvement in gastric accommodation or gastric emptying. ${ }^{225}$ Thus, it may be more effective in patients with early satiety but this remains to be proven. Buspirone, which may also increase gastric accommodation, has shown benefit in adults with FD. ${ }^{227}$ Other medications to consider are prokinetics, as FD can be associated with delayed gastric emptying. A single trial of domperidone demonstrated benefit in patients diagnosed with FAPDs, but not those with FD specifically. ${ }^{210}$ Another commonly prescribed medication for FD is amitriptyline; this medication has shown benefit in adults with FD, although a single trial found no benefit in pediatric FD patients. ${ }^{221,228}$ The maximum dose utilized in that trial was $20 \mathrm{mg}$ and it is possible that a better response may be seen at higher doses such as those commonly used in clinical practice. If considering amitriptyline, it is 

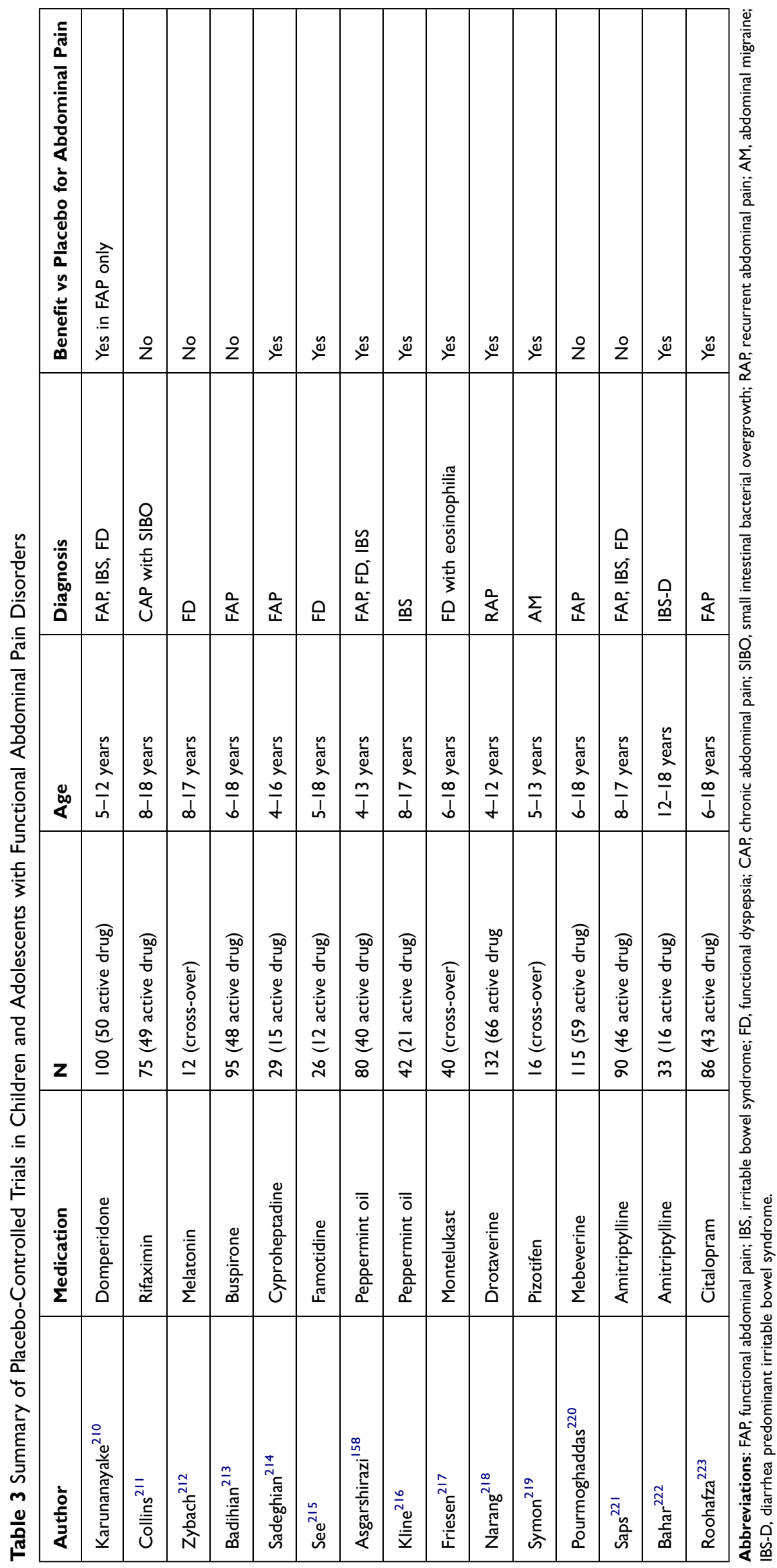
recommended to get, at least, a baseline electrocardiogram to evaluate for prolonged QT. ${ }^{229,230}$ Benefit has been demonstrated for montelukast for FD patients with duodenal eosinophilia.

\section{IBS}

Psychologic treatment and trials of dietary restriction (particularly in patients with IBS-D) are a common initial approach but often medications have a positive role in the treatment of IBS. In addition, a trial of soluble fiber or probiotics are reasonable early treatments before beginning medications. Patients with suspected IBS-C should initially be treated with laxatives to ensure that pain does not resolve with normalization of stools (ie, that they do not have functional constipation rather than IBS-C).

In adults with IBS-C, osmotic laxatives are generally not helpful but chloride channel activators (eg, lubiprostone) and prokinetic drugs such as guanylate cyclase activators (eg, linaclotide) and 5-HT4 agonists (eg, tegaserod) are beneficial. ${ }^{64}$ In a randomized trial of children with IBS-C, comparing a laxative to a laxative plus tegaserod, both improved constipation but pain only improved in the group receiving tegaserod. ${ }^{231}$ Selective serotonin reuptake inhibitors (SSRI) anti-depressants have also been recommended in adults with IBS and may be most useful in IBS-C where tricyclic antidepressants can worsen constipation. ${ }^{129}$ In a pediatric FAP study, citalopram was superior to placebo in pain reduction and global symptom severity improvement in the per-protocol analysis but not the intention-to-treat analysis. $^{223}$

In adults with IBS-D, bile acid sequestration medication is generally not helpful but tricyclic antidepressants (TCAs), rifaximin, alosetron in certain patients, and mixed opioid agonists/antagonists are recommended. ${ }^{64}$ There are mixed recommendations regarding antispasmodics such as dicyclomine and hyoscyamine. ${ }^{64,129}$ Studies utilizing common antispasmodics are lacking in children with IBS-D and results of other antispasmodic trials are mixed. ${ }^{218,220}$ Peppermint oil which has antispasmodic properties has demonstrated efficacy in two placebocontrolled trials in FAP and IBS. ${ }^{158,216}$ Amitriptyline did not improve abdominal pain in a population with varying FAPDs including a sub-analysis of patients with IBS-D, but was likely underpowered for assessing this subgroup. ${ }^{221}$ In a study of adolescents with IBS-D, amitriptyline demonstrated benefit in improving pain, diarrhea and QOL. ${ }^{222}$

\section{Neurostimulation}

Auricular neurostimulation is a relatively new nonpharmacologic treatment for FAPDs. The enteric nervous system connects with the gut endocrine and immune system, the microbiota, and to the CNS via the vagus nerve. ${ }^{232}$ Auricular neurostimulation utilizing an FDAcleared device targets these central pathways via branches of four cranial nerves including the vagus nerve. ${ }^{233}$ Auricular neurostimulation alters CNS signal processing which in turn modulates inflammation, nociception, and autonomic functioning restoring sympathovagal balance. ${ }^{234}$ In adults with $\mathrm{FD}$, auricular stimulation has been shown to improve accommodation, increase the percentage of normal gastric slow waves, and stimulate vagal activity. ${ }^{235}$ In the long-term, it improves dyspeptic symptoms, depression, and anxiety. ${ }^{235}$ In adolescents with FAPDs, auricular neurostimulation decreases pain with sustained effects. ${ }^{233}$ In adolescents with IBS, Krasaelap and colleagues found a 59\% response rate with neurostimulation as compared to $26 \%$ in sham controls with lower composite and usual pain scores. ${ }^{236}$

\section{Putting It All Together}

Again, there are no established, evidence-based guidelines for the evaluation and management of pediatric FAPDs. We offer the following recommendations as a compilation of current evidence, adult guidelines (which are likely relevant to adolescents), and our experience with suspected FAPDs in the absence of alarm symptoms.

The approach should begin with the establishment of an FAPD diagnosis utilizing Rome IV criteria and this diagnosis should be shared with the patient and their caregivers. Treatment should begin with education, providing at least a brief overview of the biopsychosocial model, establishing the basis for recommendations.

All patients with FD or IBS should, at a minimum, be screened for anxiety, depression, and poor sleep and these targets, if identified, be intervened upon either in the context of a consultative relationship with a mental health provider in an integrated care setting or by a psychologist working independently. In the case of the latter, the referral should involve direct communication, clearly establishing goals to ensure the patient acquires positive coping skills even in the absence of a diagnosable mental health condition. Additionally, patients should be queried for sleep dysfunction. When 
Table 4 Treatment Options for Constipation-Predominant IBS (IBS-C) and Diarrhea-Predominant IBS (IBS-D)

\begin{tabular}{|l|l|}
\hline IBS-C & IBS-D \\
\hline - Soluble fiber & - Dietary restriction of fructose, \\
supplementation & lactose, and sorbitol \\
Lubiprostone & - Low FODMAP diet \\
- Probiotics (Bifidobacteria & Probiotics (Bifidobacteria and \\
and Lactobacillus) & Lactobacillus) \\
Tegaserod & - Antibiotics (rifaximin or \\
& metronidazole) \\
& - Amitriptyline \\
& - Peppermint oil \\
& - Anti-spasmodics \\
\hline
\end{tabular}

delayed onset of sleep or frequent waking is present, behavioral sleep measures should be instituted.

For patients with FD, we recommend no initial diagnostic testing. Patients should initially be treated with an $\mathrm{H} 2$ blocker or proton pump inhibitor. If pain resolves (which may be by therapeutic effect or placebo response), we recommend treating for 8-12 weeks. In patients with no response after 2-3 weeks, cyproheptadine can be added. If there is no response to this medication after, 2 3 weeks, referral to a pediatric gastroenterologist for diagnostic evaluation should be considered.

For patient with IBS, initial evaluation including celiac serology and in the presence of diarrhea, stool calprotectin (or lactoferrin) is reasonable. For patients with suspected IBS-C, constipation should be initially treated with laxatives to establish the diagnosis. If pain resolves with resolution of the constipation, then the diagnosis is functional constipation and not IBS-C. The treatment approach then depends on whether symptoms are predominantly associated with constipation or diarrhea. We have summarized treatment options in Table 4. In the absence of alarm symptoms, IBS patients are probably best served by multiple intervention trials before undertaking further diagnostic testing, particularly colonoscopy. If patients are responsive to diet restrictions, they should be evaluated by a dietician to ensure the nutritional adequacy of the restricted diet.

\section{Conclusion}

As diagnostic evaluation of FAPDs can be costly and given that FAPDs are intended to be positive diagnoses not necessarily requiring tests to rule out disease, there is certainly a push to reduce "unnecessary" testing and contain costs. Ultimately, the cost of care must be weighed against the cost of inadequate evaluation and treatment, namely, impaired social, academic, and emotional functioning that is likely in the context of ongoing pain. Despite the high prevalence of FAPDs and a reasonably large body of scientific data, there remain significant questions to address, including which evaluations provide information that contributes to better patient outcomes. The issue is not just whether a test is costly, but whether the test provides value from the patient perspective, improving outcomes that justify the expense. There is also a need to study the commonly used medications and, to implement a precision therapeutics approach to determine which drugs work in which patients and at what dose and how to best combine biologic, psychologic, and social interventions tailored to the specific pain contributors of the individual patient. While we have attempted to provide an update across a wide number of important clinical areas for FAPDs, we suspect and hope there will be significant new developments over the next decade.

\section{Disclosure}

The authors report no conflicts of interest in this work.

\section{References}

1. Chitkara DK, Rawat DJ, Talley NJ. The epidemiology of childhood recurrent abdominal pain in Western countries: a systematic review. Am J Gastroenterol. 2005;100(8):1868-1875. doi:10.1111/j.15720241.2005.41893.x

2. Varni JW, Bendo CB, Nurko S, et al. Health-related quality of life in pediatric patients with functional and organic gastrointestinal diseases. J Pediatr. 2015;166(1):85-90. doi:10.1016/j.jpeds.2014.08.022

3. Korterink JJ, Diederen K, Benninga MA, Tabbers MM. Epidemiology of pediatric functional abdominal pain disorders: a meta-analysis. PLoS One. 2015;10(5):e126982. doi:10.1371/journal.pone.0126982

4. Hyams JS, Di Lorenzo C, Saps M, Shulman RJ, Staiano A, van Tilburg M. Childhood gastrointestinal disorders: child/adolescent. Gastroenterology. 2016;150(6):1456-1468. doi:10.1053/j. gastro.2016.02.015

5. Walker LS, Lipani TA, Greene JW, et al. Recurrent abdominal pain: symptom subtypes based on the Rome II criteria for pediatric functional gastrointestinal disorders. J Pediatr Gastroenterol Nutr. 2004;38 (2):187-191. doi:10.1097/00005176-200402000-00016

6. Schurman JV, Friesen CA, Danda CE, et al. Diagnosing functional abdominal pain with the Rome II criteria: parent, child, and clinician agreement. J Pediatr Gastroenterol Nutr. 2005;41(3):291-295. doi:10.1097/01.mpg.0000178438.64675.c4

7. Rasquin A, Di Lorenzo C, Forbes D, et al. Childhood functional gastrointestinal disorders: child/adolescent. Gastroenterology. 2006;130(5):1527-1537. doi:10.1053/j.gastro.2005.08.063

8. Baaleman DF, Di Lorenzo C, Benninga MA, Saps M. The effects of the Rome IV criteria on pediatric gastrointestinal practice. Curr Gastroenterol Rep. 2020;22(5):21. doi:10.1007/s11894-020-007 60-8 
9. Schurman JV, Hunter HL, Friesen CA. Conceptualization and treatment of chronic abdominal pain in pediatric gastroenterology practice. J Pediatr Gastroenterol Nutr. 2010;50(1):32-37. doi:10.1097/MPG.0b013e3181ae3610

10. Chogle A, Dhroove G, Sztainberg M, Di Lorenzo C, Saps M. How reliable are the Rome III criteria for the assessment of functional gastrointestinal disorders in children? $\mathrm{Am}$ J Gastroenterol. 2015;105(12):2697-2701.

11. Trivić I, Hojsak I. Initial diagnosis of functional gastrointestinal disorders in children increases a chance for resolution of symptoms. Pediatr Gastroenterol Hepatol Nutr. 2018;21 (4):264-270. doi:10.5223/pghn.2018.21.4.264

12. Edwards T, Friesen C, Schurman JV. Classification of pediatric functional gastrointestinal disorders related to abdominal pain using Rome III vs. Rome IV criterions. BMC Gastroenterol. 2018;18(1):41. doi:10.1186/s12876-018-0769-z

13. Friesen CA, Rosen JM, Schurman JV. Prevalence of overlap syndromes and symptoms in pediatric functional dyspepsia. BMC Gastroenterol. 2016;16(1):75. doi:10.1186/s12876-016-0495-3

14. Russell AC, Stone AL, Walker LS. Nausea in children with functional abdominal pain predicts poor health outcomes in young adulthood. Clin Gastroenterol Hepatol. 2017;15 (5):706-711. doi:10.1016/j.cgh.2016.07.006

15. Kovacic K, Williams S, Li BUK, Chelimsky G, Miranda A. High prevalence of nausea in children with pain-associated functional gastrointestinal disorders: are Rome criteria applicable. J Pediatr Gastroenterol Nutr. 2013;57(3):311-315. doi:10.1097/ MPG.0b013e3182964203

16. Kovacic K, Kapavarapu PK, Sood MR, et al. Nausea exacerbates symptoms burden, quality of life, and functioning in adolescents with abdominal pain disorders. Neurogastroenterol Motil. 2019;31(7):e13595. doi:10.1111/nmo.13595

17. Friesen C, Singh M, Singh V, Schurman JV. A cross-sectional study of nausea in functional abdominal pain: relation to mucosal mast cells and psychological functioning. BMC Gastroenterol. 2020;20(1):144. doi:10.1186/s12876-020-01291-2

18. Di Lorenzo C, Youssef NN, Sigurdsson L, Scharff L, Griffiths J, Wald A. Visceral hyperalgesia in children with functional abdominal pain. J Pediatr. 2001;139(6):838-843. doi:10.1067/mpd.2001.118883

19. Van Ginkel R, Voskuijl WP, Benninga MA, Taminiau JA, Boeckxstaens GE. Alterations in rectal sensitivity and motility in childhood irritable bowel syndrome. Gastroenterology. 2001;120(1):31-38. doi:10.1053/gast.2001.20898

20. Halac U, Noble A, Faure C. Rectal sensory threshold for pain is a diagnostic marker of irritable bowel syndrome and functional abdominal pain in children. $J$ Pediatr. 2010;156(1):60-65. doi:10.1016/j.jpeds.2009.06.062

21. Samsom M, Verhagen MA, vanBerge Henegouwen GP, Smout AJ. Abnormal clearance of exogenous acid and increased acid sensitivity of the proximal duodenum in dyspeptic patients. Gastroenterology. 1999;116(3):515-520. doi:10.1016/S00165085(99)70171-X

22. Miwa H, Nakajima K, Yamaguchi K, Fujimoto K. Generation of dyspeptic symptoms by direct acid infusion into the stomach of healthy Japanese subjects. Aliment Pharmacol Ther. 2007;26 (2):257-264. doi:10.1111/j.1365-2036.2007.03367.x

23. Oshima T, Okugawa T, Tomita $T$, et al. Generation of dyspeptic symptoms by direct acid and water infusion into the stomachs of functional dyspepsia patients and healthy subjects. Aliment Pharmacol Ther. 2012;35(1):175-182. doi:10.1111/j.13652036.2011.04918.x

24. Lee KJ, Demarchi B, Demedts I, Sifrim D, Raeymaekers P, Tack J. A pilot study on duodenal acid exposure and its relationship to symptoms in functional dyspepsia with prominent nausea. Am J Gastroenterol. 2004;99(9):1765-1773. doi:10.1111/j.15720241.2004.30822.x
25. Ishii M, Manabe N, Kusunoki H, et al. Real-time evaluation of dyspeptic symptoms and gastric motility induced by duodenal acidification using noninvasive transnasal endoscopy. J Gastroenterol. 2008;43(12):935-941. doi:10.1007/s00535-0082303-5

26. Feinle C, Meier O, Otto B, D'Amato M, Fried M. Role of duodenal lipid and cholecystokinin A receptors in the pathophysiology of functional dyspepsia. Gut. 2001;48(3):347-355.

27. Rosen JM, Cocjin JT, Schurman JV, Colombo JM, Friesen CA. Visceral hypersensitivity and electromechanical dysfunction as therapeutic targets in pediatric functional dyspepsia. World $J$ Gastrointest Pharmacol Ther. 2014;5(3):122-138. doi:10.4292/wjgpt.v5.i3.122

28. Krammer L, Sergeevna Sowa A, Lorentz A. Mast cells in irritable bowel syndrome: a systematic review. $J$ Gastrointestin Liver Dis. 2019;28(4):463-472. doi:10.15403/jgld-229

29. Du L, Chen B, Kim JJ, Chen X, Dai N. Micro-inflammation in functional dyspepsia: a systematic review and meta-analysis. Neurogastroenterol Motil. 2018;30(4):e13304. doi:10.1111/ nmo. 13304

30. Friesen CA, Schurman JV, Colombo JM, Abdel-Rahman SM. Eosinophils and mast cells as therapeutic targets in pediatric functional dyspepsia. World $J$ Gastrointest Pharmacol Ther. 2013;4(4):86-96. doi:10.4292/wjgpt.v4.i4.86

31. Wouters MM, Balemans D, Van Wanrooy S, et al. Histamine receptor H1-mediated sensitization of TRPV1 mediates visceral hypersensitivity and symptoms in patients with irritable bowel syndrome. Gastroenterology. 2016;150(4):875-887. doi:10.1053/ j.gastro.2015.12.034

32. Akbar A, Yiangou Y, Facer P, Walters JRF, Anand P, Ghosh S. Increased capsaicin receptor TRPV1-expressing sensory fibres in irritable bowel syndrome and their correlation with abdominal pain. Gut. 2008;57(7):923-929. doi:10.1136/gut.2007.138982

33. Schurman JV, Singh M, Singh V, Neilan N, Friesen CA. Symptoms and subtypes in pediatric functional dyspepsia: relation to mucosal inflammation and psychological functioning. J Pediatr Gastroenterol Nutr. 2010;51(3):298-303. doi:10.1097/ MPG.0b013e3181d1363c

34. Singh M, Singh V, Schurman JV, Colombo JM, Friesen CA. The relationship between mucosal inflammatory cells, specific symptoms, and psychological functioning in youth with irritable bowel syndrome. Sci Rep. 2020;10(1):11988. doi:10.1038/s41598-02068961-9

35. Pittayanon R, Lau JT, Yuan Y, et al. Gut microbiota in patients with irritable bowel syndrome- A systematic review. Gastroenterology. 2019;157(1):97-108. doi:10.1053/j. gastro.2019.03.049

36. Hollister EB, Oezguen N, Chumpitazi BP, et al. Leveraging human microbiome features to diagnose and stratify children with irritable bowel syndrome. $J$ Mol Diagn. 2019;21 (3):449-461. doi:10.1016/j.jmoldx.2019.01.006

37. Shin A, Preidis GA, Shulman R, Kashyap PC. The gut microbiome in adult and pediatric functional gastrointestinal disorders. Clin Gastroenterol Hepatol. 2019;17(2):256-274. doi:10.1016/j. cgh.2018.08.054

38. Martin CR, Osadchiy V, Kalani A, Mayer EA. The brain-gutmicrobiome axis. Cell Mol Gastroenterol Hepatol. 2018;6 (2):133-148. doi:10.1016/j.jcmgh.2018.04.003

39. Hanning $\mathrm{N}$, Edwinson $\mathrm{AL}$, Ceuleers $\mathrm{H}$, et al. Intestinal barrier dysfunction in irritable bowel syndrome: a systematic review. Therap Adv Gastroenterol. 2021;14:1756284821993586. doi: $10.1177 / 1756284821993586$

40. Hollier JM, van Tilburg MAL, Liu Y, et al. Multiple psychological factors predict abdominal pain severity in children with irritable bowel syndrome. Neurogastroenterol Motil. 2019;31(2): e13509. doi:10.1111/nmo.13509 
41. Newton E, Schosheim A, Patel S, Chitkara DK, van Tilburg MAL. The role of psycohological factors in pediatric functional abdominal pain disorders. Neurogastroenterol Motil. 2019;31:e13538. doi:10.1111/nmo.13538

42. Deacy AD, Friesen CA, Staggs VS, Schurman JV. Evaluation of clinical outcomes in an interdisciplinary abdominal pain clinic: a retrospective, exploratory review. World J Gastroenterol. 2019;25(24):3079-3090. doi:10.3748/wjg.v25.i24.3079

43. Jones MP, Tack J, Van Oudenhove L, et al. Mood and anxiety disorders precede development of functional gastrointestinal disorders in patients but not in the population. Clin Gastroenterol Hepatol. 2017;15(7):1014-1020. doi:10.1016/j.cgh.2016.12.032

44. Zhao W, Jin $\mathrm{H}, \mathrm{Xu} \mathrm{M}$, et al. Sleep quality of functional gastrointestinal disorder patients in class-three hospitals: a cross-sectional study in Tianjin, China. Biomed Res Int. 2018;2018:3619748. doi:10.1155/2018/3619748

45. Balikji S, Mackus M, Brookhuis KA, et al. The association of insomnia, perceived immune functioning, and irritable bowel syndrome complaints. J Clin Med. 2018;7(9):238. doi:10.3390/jcm7090238

46. Buchanan DT, Cain K, Heitkemper M, et al. Sleep measures predict next-day symptoms in women with irritable bowel syndrome. J Clin Sleep Med. 2014;10(9):1003-1009. doi:10.5664/jcsm.4038

47. Schurman JV, Friesen CA, Dai H, Danda CE, Hyman PE, Cocjin JT. Sleep problems and functional disability in children with functional gastrointestinal disorders: an examination of the potential mediating effects of physical and emotional symptoms. BMC Gastroenterol. 2012;12:142. doi:10.1186/1471-230X-12-142

48. Schurman JV, Friesen CA. Identifying potential pediatric chronic abdominal pain triggers using ecological momentary assessment. Clin Prac Pediatr Psychol. 2015;3:131-141. doi:10.1037/ cpp0000095

49. Ali T, Choe J, Awab A, Wagener TL, Orr WC. Sleep, immunity and inflammation in gastrointestinal disorders. World J Gastroenterol. 2013;19(48):9231-9239. doi:10.3748/wjg.v19. i48.9231

50. Vriend J, Davidson F, Rusak B, Corkum P. Emotional and cognitive impact of sleep restriction in children. Sleep Med Clin. 2015;10(2):107-115. doi:10.1016/j.jsmc.2015.02.009

51. Hetterich L, Stengel A. Psychotherapeutic interventions in irritable bowel syndrome. Front Psychiatry. 2020;11:286. doi:10.3389/ fpsyt.2020.00286

52. Hale AE, Smith AM, Snyder Christiana J, et al. Perceptions of pain treatment in pediatric patients with functional gastrointestinal disorders. Clin J Pain. 2020;36(7):550-557. doi:10.1097/ AJP.0000000000000832

53. Friesen CA, Colombo JM, Schurman JV. The evolving role of mucosal histology in the evaluation of pediatric functional dyspepsia: a review. Gastrointest Disord. 2019;1(1):176-190. doi:10.3390/gidisord1010013

54. El-Chammas K, Majeskie A, Simpson P, Sood M, Miranda A. Red flags in children with chronic abdominal pain and Crohn's disease- a single center experience. $J$ Pediatr. 2013;162 (4):783-787. doi:10.1016/j.jpeds.2012.09.014

55. Choi YJ, Jeong SJ. Is fecal calprotectin always normal in children with irritable bowel syndrome? Intest Res. 2019;17(4):546-553. doi:10.5217/ir.2019.00009

56. Campbell JP, Zierold C, Rode AM, Blocki FA, Vaughn BP. Clinical performance of a novel LIAISON fecal calprotectin assay for differentiation of inflammatory bowel disease from irritable bowel syndrome. J Clin Gastroenterol. 2021;55 (3):239-243. doi:10.1097/MCG.0000000000001359

57. Carrasco-Labra A, Lytvyn L, Falck-Ytter Y, Surawicz CM, Chey WD. AGA technical evaluation review on the evaluation of functional diarrhea and diarrhea-predominant irritable bowel syndrome in adults (IBS-D). Gastroenteroogy. 2019;157 (3):859-880.
58. Menees SB, Powell C, Kurlander J, Goel A, Chey WD. A meta-analysis of the utility of C-reactive protein, erythrocyte sedimentation rate, fecal calprotectin, and fecal lactoferrin to exclude inflammatory bowel disease in adults with IBS. Am J Gastroenterol. 2015;110(3):444-454. doi:10.1038/ajg.2015.6

59. Pfefferkorn MD, Boone JH, Nguyen JT, Juliar BE, Davis MA, Parker KK. Utility of fecal lactoferrin in identifying Crohn disease activity in children. J Pediatr Gastroenterol Nutr. 2010;51 (4):425-428. doi:10.1097/MPG.0b013e3181d67e8f

60. Borkowska A, Liberek A, Łuczak G, Jankowska A, Plata-Nazar K, Korzon M. Kanińska. Fecal lactoferrin, a marker of intestinal inflammation in children with inflammatory bowel disease. Acta Biochim Pol. 2015;62(3):541-545. doi:10.18388/abp.2015_982

61. Ho SSC, Ross M, Keenan JI, Day AS. Fecal calprotectin in combination with standard blood tests in the diagnosis of inflammatory bowel disease in children. Front Pediatr. 2021;8:609279. doi:10.3389/fped.2020.609279

62. Cristofori F, Fontana C, Magistà A, et al. Increased prevalence of celiac disease among pediatric patients with irritable bowel syndrome: a 6-year prospective cohort study. JAMA Pediatr. 2014;168(6):555-560. doi:10.1001/jamapediatrics.2013.4984

63. Kansu A, Kuloğlu Z, Demir A, Yaman A, Turkish Celiac Study Group. Yield of coeliac screening in abdominal pain- associated functional gastrointestinal system disorders. J Paediatr Child Health. 2015;51(11):1066-1070. doi:10.1111/jpc.12929

64. Lacy BE, Pimentel M, Brenner DM, et al. ACG clinical guideline: management of irritable bowel syndrome. Am J Gastroenterol. 2021;116(1):17-44. doi:10.14309/ajg.0000000000001036

65. Chumpitazi BP, Weidler EM, Lu DY, Tsai CM, Shulman RJ. Selfperceived food intolerances are common and associated with clinical severity in childhood irritable bowel syndrome. J Acad Nutr Diet. 2016;116(9):1458-1464. doi:10.1016/j.jand.2016.04.017

66. Chumpitazi BP. Update on dietary management of childhood functional abdominal pain disorders. Gastroenterol Clin North Am. 2018;47(4):715-726. doi:10.1016/j.gtc.2018.07.001

67. Zhou SY, Gillilland M, Wu X. FODMAP diet modulates visceral nociception by lipopolysaccharide-mediated intestinal inflammation and barrier dysfunction. J Clin Invest. 2018;128(1):267-280. doi:10.1172/JCI92390

68. El-Salhy M, Gundersen D. Diet in irritable bowel syndrome. Nutr J. 2015;14:36. doi:10.1186/s12937-015-0022-3

69. Turco R, Salvatore S, Miele E, Romano C, Marseglia GL, Staiano A. Does a low FODMAPs diet reduce symptoms of functional abdominal pain disorders? A systematic review in adult and paediatric population, on behalf of Italian Society of Pediatrics. Ital J Pediatr. 2018;44(1):53. doi:10.1186/s13052018-0495-8

70. O'Keeffe M, Jansen C, Martin L, et al. Long-term impact of the low-FODMAP diet on gastrointestinal symptoms, dietary intake, patient acceptability, and healthcare utilization in irritable bowel syndrome. Neurogastroenterol Motil. 2018;30(1):e13154. doi:10.1111/nmo.13154

71. Masuy I, Van Oudenhove L, Tack J, Biesiekierski JR. Effect of intragastric FODMAP infusion on upper gastrointestinal motility, gastrointestinal, and psychological symptoms in irritable bowel syndrome vs healthy controls. Neurogastroenterol Motil. 2018;30 (1):e13167. doi:10.1111/nmo.13167

72. Chumpitazi BP, McMeans AR, Vaughan A, et al. Fructans exacerbate symptoms in a subset of children with irritable bowel syndrome. Clin Gastroenterol Hepatol. 2017. doi:10.1016/j. cgh.2017.09.043

73. Chumpitazi BP, Cope JL, Hollister EB, et al. Randomised clinical trial: gut microbiome biomarkers are associated with clinical response to a low FODMAP diet in children with the irritable bowel syndrome. Aliment Pharmacol Ther. 2015;42(4):418-427. doi:10.1111/apt.13286 
74. Valeur J, Småstuen MC, Knudsen T, Lied GA, Røseth AG. Exploring gut microbiota composition as an indicator of clinical response to dietary FODMAP restriction in patients with irritable bowel syndrome. Dig Dis Sci. 2018;63(2):429-436. doi:10.1007/ s10620-017-4893-3

75. Chumpitazi BP. The gut microbiome as a predictor of low FODMAP diet efficacy in functional bowel disorders. Curr Opin Gastroenterol. 2020;36(2):147-154.

76. Hill P, Muir JG, Gibson PR. Controversies and recent developments of the low-FODMAP diet. Gastroenterol Hepatol. 2017;13 (1):36-45.

77. Staudacher HM, Lomer MCE, Farquharson FM, et al. A diet low in FODMAPs reduces symptoms in patients with irritable bowel syndrome and a probiotic restores Bifidobacterium species: a randomized controlled trial. Gastroenterology. 2017;153 (4):936-947. doi:10.1053/j.gastro.2017.06.010

78. Chey WD, Keefer L, Whelan K, Gibson PR. Behavioral and diet therapies in integrated care for patients with irritable bowel syndrome. Gastroenterology. 2021;160(1):47-62. doi:10.1053/j. gastro.2020.06.099

79. Dimidi E, Whelan K. Food supplements and diet as treatment options in irritable bowel syndrome. Neurogastroenterol Motil. 2020;32(8):e13951. doi:10.1111/nmo.13951

80. Järbrink-Sehgal ME, Talley NJ. Duodenal and rectal eosinophilia are new biomarkers of nonceliac gluten sensitivity. Clin Gastroenterol Hepatol. 2019;17(4):613-615. doi:10.1016/j. cgh.2018.11.039

81. Tuck CJ, Vanner SJ. Dietary therapies for functional bowel symptoms: recent advances, challenges, and future directions. Neurogastroenterol Motil. 2018;30(1):13238. doi:10.1111/ nmo. 13238

82. Shahbazkhani B, Fanaeian MM, Farahvash MJ, et al. Prevalence of non-celiac gluten sensitivity in patients with refractory functional dyspepsia: a randomized double-blind placebo controlled trial. Sci Rep. 2020;10:2401. doi:10.1038/s41598-020-59532-z

83. Francavilla R, Cristofori F, Verzillo L, et al. Randomized double-blind placebo-controlled crossover trial for the diagnosis of non-celiac gluten sensitivity in children. Am J Gastroenterol. 2018;113(3):421-430. doi:10.1038/ajg.2017.483

84. Carroccio A, Giannone G, Mansueto P, et al. Duodenal and rectal mucosa inflammation in patients with non-celiac wheat sensitivity. Clin Gastroenterol Hepatol. 2019;17(4):682-690. doi:10.1016/j.cgh.2018.08.043

85. Giancola F, Volta U, Repossi R, et al. Mast cell-nerve interactions correlate with bloating and abdominal pain severity in patients with non-celiac gluten/wheat sensitivity. Neurogastroenterol Motil. 2020;32(6):e13814. doi:10.1111/nmo.13814

86. Bonder MJ, Tigchelaar EF, Cai X, et al. The influence of a short-term gluten-free diet on the human gut microbiome. Genome Med. 2016;8(1):45. doi:10.1186/s13073-016-0295-y

87. Di Liberto D, Carlisi D, D'Anneo A, et al. Gluten free diet for the management of non celiac diseases: the two sides of the coin. Healthcare. 2020;8(4):400. doi:10.3390/healthcare 8040400

88. Skodje GI, Sarna VK, Minelle IH, et al. Fructan, rather that gluten, induces symptoms in patients with self-reported non-celiac gluten sensitivity. Gastroenterology. 2018;154 (3):529-539.e2. doi:10.1053/j.gastro.2017.10.040

89. El-Chammas K, Williams SE, Miranda A. Disaccharidase deficiencies in children with chronic abdominal pain. JPEN J Parenter Enteral Nutr. 2017;41(3):463-469. doi:10.1177/ 0148607115594675

90. Chumpitazi BP, Robayo-Torres CC, Tsai CM, et al. Demographic and clinical correlates of mucosal disaccharidase deficiencies in children with functional dyspepsia. J Pediatr Gastroenterol Nutr. 2018;66 (Suppl 3):S52-S55. doi:10.1097/MPG.0000000000001859
91. Colombo JM, Friesen CS, Garg U, Friesen CA, San Pablo W. Relationships between disaccharidase deficiencies, duodenal inflammation and symptom profile in children with abdominal pain. Sci Rep. 2021;11:4902. doi:10.1038/s41598-021-84535-9

92. Chumpitazi BP, Shulman RJ. Dietary carbohydrates and childhood functional abdominal pain. Ann Nutr Metab. 2016;68(Suppl 1):8-17. doi:10.1159/000445390

93. Martinez-Azcona O, Moreno-álvarez A, Seoane-Pillado T, et al. Fructose malabsorption in asymptomatic children and in patients with functional chronic abdominal pain: a prospective comparative study. Eur J Pediatr. 2019;178(9):1395-1403. doi:10.1007/ s00431-019-03418-4

94. Hammer V, Hammer K, Memaran N, Huber WD, Hammer K, Hammer J. Relationship between abdominal symptoms and fructose ingestion in children with chronic abdominal pain. Dig Dis Sci. 2018;63(5):1270-1279. doi:10.1007/s10620-0184997-4

95. Wintermeyer P, Baur M, Pilic D, Schmidt-Choudhury A, Zilbauer M, Wirth S. Fructose malabsorption in children with recurrent abdominal pain: positive effects of dietary treatment. Klin Padiatr. 2012;224(1):17-21. doi:10.1055/ s-0031-1279747

96. Wirth S, Klodt C, Wintermeyer P, et al. Positive or negative breath test results do not predict response to fructose restricted diet in children with recurrent abdominal pain: results from a prospective randomized trial. Klin Padiatr. 2014;226 (5):268-273. doi:10.1055/s-0034-1383653

97. Escobar MA, Lustig D, Pflugeisen BM, et al. Fructose intolerance/malabsorption and recurrent abdominal pain in children. J Pediatr Gastroenterol Nutr. 2014;58(4):498-501. doi:10.1097/ MPG.0000000000000232

98. Glatstein M, Reif S, Scolnik D, et al. Lactose breath test in children: relationship between symptoms during the test and test results. Am J Ther. 2018;25(2):e189-e193. doi:10.1097/ MJT.0000000000000463

99. Krieger-Grübel C, Hutter S, Hiestand M, Brenner I, Güsewell S, Borovicka J. Treatment efficacy of a low FODMAP diet compared to a low lactose diet in IBS: a randomized, cross-over designed study. Clin Nutr ESPEN. 2020;40:83-89. doi:10.1016/ j.clnesp.2020.09.020

100. Posovszky C, Roesler V, Becker S, et al. Roles of lactose and fructose malabsorption and dietary outcomes in children presenting with chronic abdominal pain. Nutrients. 2019;11(12):3063. doi:10.3390/nu11123063

101. Gijsbers CFM, Kneepkens CMF, Büller HA. Lactose and fructose malabsorption in children with recurrent abdominal pain: results of double-blinded testing. Acta Paediatr. 2012;101(9):e411-e415. doi:10.1111/j.1651-2227.2012.02721.x

102. Yang J, Fox M, Cong Y, et al. Lactose intolerance in irritable bowel syndrome patients with diarrhoea: the roles of anxiety, activation of the innate mucosal immune system and visceral sensitivity. Aliment Pharmacol Ther. 2014;39(3):302-311. doi:10.1111/apt.12582

103. Kamphuis JBJ, Guiard B, Leveque $M$, et al. Lactose and fructo-oligosaccharides increase visceral sensitivity in mice via glycation processes, increasing mast cell density in colonic mucosa. Gastroenterology. 2020;158(3):652-663. doi:10.1053/j. gastro.2019.10.037

104. Singh M, Singh V, Friesen CA. Colonic mucosal inflammatory cells in children and adolescents with lactase deficiency. Pathol Res Pract. 2020;216(6):152971. doi:10.1016/j.prp.2020.152971

105. Sun J, Lin J, Parashette K, Zhang J, Fan R. Association of lymphocytic colitis and lactase deficiency in pediatric population. Pathol Res Pract. 2015;211(2):138-144. doi:10.1016/j.prp.2014.11.009 
106. Robayo-Torres CC, Diaz-Sotomayor M, Hamaker BR, et al. 13Clabeled-starch breath test in congenital sucrase-isomaltase deficiency. J Pediatr Gastroenterol Nutr. 2018;66(Suppl 3):S61S64. doi:10.1097/MPG.0000000000001858

107. Rathod S, Friesen CA, Radford K, Colombo JM. Sucrase breath testing in children presenting with chronic abdominal pain. Clin Pediatr (Phila). 2020;59(13):1191-1194. doi:10.1177/ 0009922820942183

108. Zheng T, Eswaran S, Photenhauer AL, Merchant JL, Chey WD, D'Amato M. Reduced efficacy of low FODMAPs diet in patients with IBS-D carrying sucrase-isomaltase (SI) hypomorphic variants. Gut. 2020;69(2):397-398. doi:10.1136/gutjnl-2018-318036

109. Henström M, Diekmann L, Bonfiglio F, et al. Functional variants in the sucrase-isomaltase gene associate with increased risk of irritable bowel syndrome. Gut. 2018;67(2):263-270. doi:10.1136/ gutjnl-2016-312456

110. Nilholm C, Roth B, Ohlsson B. A dietary intervention with reduction of starch and sucrose leads to reduced gastrointestinal and extra-intestinal symptoms in IBS patients. Nutrients. 2019;11 (7):1662. doi:10.3390/nu11071662

111. Nilholm C, Larsson E, Sonestedt E, Roth B, Ohlsson B. Assessment of a 4-week starch- and sucrose-reduced diet and it $\mathrm{s}$ effects on gastrointestinal symptoms and inflammatory parameters among patients with irritable bowel syndrome. Nutrients. 2021;13(2):416. doi:10.3390/nu13020416

112. Feinle C, Meier O, Otto B, D'Amato M, Fried M. Role of duodenal lipid and cholecystokinin A receptors in the pathophysiology of functional dyspepsia. Gut. 2001;48(3):347-355. doi:10.1136/gut.48.3.347

113. Simrén M, Agerforz P, Björnsson ES, Abrahamsson H. Nutrientdependent enhancement of rectal sensitivity in irritable bowel syndrome (IBS). Neurogastroenterol Motil. 2007;19(1):20-29. doi:10.1111/j.1365-2982.2006.00849.x

114. Feinle-Bisset C, Azpiroz F. Dietary lipids and functional gastrointestinal disorders. Am J Gastroenterol. 2013;108(5):737-747. doi:10.1038/ajg.2013.76

115. Pilichiewicz AN, Feltrin KL, Horowitz M, et al. Functional dyspepsia is associated with a greater symptomatic response to fat but not carbohydrate, increasing fasting and postprandial CCK, and diminished PYY. Am J Gastroenterol. 2008;103 (10):2613-2623. doi:10.1111/j.1572-0241.2008.02041.x

116. Lee IS, Kullmann S, Scheffler K, Preissl H, Enck P. Fat label compared with fat content: gastrointestinal symptoms and brain activity in functional dyspepsia patients and healthy controls. Am J Clin Nutr. 2018;108(1):127-135. doi:10.1093/ajcn/nqy077

117. Lee SY, Masaoka T, Han HS, et al. A prospective study on symptom generation according to spicy food intake and TRPV1 genotypes in functional dyspepsia patients. Neurogastroenterol Motil. 2016;28(9):1401-1408. doi:10.1111/nmo.12841

118. Esmaillzadeh A, Keshteli AH, Hajishafiee M, Feizi A, FeinleBisset C, Adibi P. Consumption of spicy foods and the prevalence of irritable bowel syndrome. World J Gastroenterol. 2013;19 (38):6465-6471. doi:10.3748/wjg.v19.i38.6465

119. Gonlachanvit S, Mahayosnond A, Kullavanijaya P. Effects of chili on postprandial gastrointestinal symptoms in diarrhoea predominant irritable bowel syndrome: evidence for capsaicin-sensitive visceral nociception hypersensitivity. NeurogastroenterolMmotil. 2009;21(1):23-32.

120. Hammer J, Führer M. Clinical characteristics of functional dyspepsia depending on chemosensitivity to capsaicin. Neurogastroenterol Motil. 2017;29(10):1-12. doi:10.1111/ nmo. 13103

121. Führer M, Vogelsang H, Hammer J. A placebo-controlled trial fo an oral capsaicin load in patients with functional dyspepsia. Neurogastroenterol Motil. 2011;23(10):918-e397. doi:10.1111/ j.1365-2982.2011.01766.x
122. Hammer J, Führer M, Pipal L, Matiasek J. Hypersensitivity for capsaicin in patients with functional dyspepsia. Neurogastroenterol Motil. 2008;20(2):125-133.

123. Hammer J. Identification of individuals with functional dyspepsia with a simple, minimally invasive test: a single center cohort study of the oral capsaicin test. Am J Gastroenterol. 2018;113 (4):584-592. doi:10.1038/ajg.2018.16

124. van Wanrooij SJM, Wouters MM, Van Oudenhove L, et al. Sensitivity testing in irritable bowel syndrome with rectal capsaicin stimulations: role of TRPV1 upregulation and sensitization in visceral hypersensitivity? Am J Gastroenterol. 2014;109 (1):99-109. doi:10.1038/ajg.2013.371

125. Leonel AJ, Alvarez-Leite JI. Butyrate: implications for intestinal function. Curr Opin Clin Nutr Metab Care. 2012;15(5):474-479. doi:10.1097/MCO.0b013e32835665fa

126. Sivaprakasam S, Prasad PD, Singh N. Benefits of short-chain fatty acids and their receptors in inflammation and carcinogenesis. Pharmacol Ther. 2016;164:144-151. doi:10.1016/j.pharmthera.2016.04.007

127. Folkerts J, Stadhouders R, Redegeld FA, et al. Effect of dietary fiber and metabolites on mast cell activation and mast cell-associated diseases. Front Immunol. 2018;9:1067. doi:10.3389/fimmu.2018.01067

128. Nagarajan N, Morden A, Bischof D. The role of fiber supplementation in the treatment of irritable bowel syndrome: a systematic review and meta-analysis. Eur J Gastroenterol Hepatol. 2015;27 (9):1002-1010. doi:10.1097/MEG.0000000000000425

129. Moayyedi P, Andrews CN, MacQueen G, et al. Canadian Association of Gastroenterology clinical practice guideline for the management of irritable bowel syndrome. (IBS). J Can Assoc Gastroenterol. 2019;2(1):6-29. doi:10.1093/jcag/gwy071

130. Wegh CAM, Schoterman MHC, Vaughan EE, Belzer C, Benninga MA. The effect of fiber and prebiotics on children's gastrointestinal disorders and microbiome. Expert Rev Gastroenterol Hepatol. 2017;11(11):1031-1045. doi:10.1080/ 17474124.2017.1359539

131. Feldman W, McGrath P, Hodgson C, Ritter H, Shipman RT. The use of dietary fiber in the management of simple, childhood, idiopathic, recurrent, abdominal pain. Results in a prospective, double-blind, randomized, controlled trial. Am J Dis Child. 1985;139 (12):1216-1218. doi:10.1001/archpedi.1985.02140140050025

132. Horvath A, Dziechciarz P, Szajewska H. Glucomannan for abdominal pain-related functional gastrointestinal disorders in children: a randomized trial. World J Gastroenterol. 2013;19 (20):3062-3068. doi:10.3748/wjg.v19.i20.3062

133. Christensen MF. Recurrent abdominal pain and dietary fiber. $A m$ J Dis Child. 1986;140(8):738-739.

134. Shulman RJ, Hollister EB, Cain K, et al. Psyllium fiber reduces abdominal pain in children with irritable bowel syndrome in a randomized, double-blind trial. Clin Gastroenterol Hepatol. 2017;15(5):712-719.e4. doi:10.1016/j.cgh.2016.03.045

135. Romano C, Comito D, Famiani A, Calamarà S, Loddo I. Partially hydrolyzed guar gum in pediatric functional abdominal pain. World J Gastroenterol. 2013;19(2):235-240. doi:10.3748/wjg.v19.i2.235

136. Park MI, Camilleri M. Is there a role of food allergy in irritable bowel syndrome and functional dyspepsia? A systematic review. Neurogastroenterol Motil. 2006;18(8):595-607. doi:10.1111/ j.1365-2982.2005.00745.x

137. Mansueto P, D'Alcamo A, Seidita A, Carroccio A. Food allergy in irritable bowel syndrome: the case of non-celiac wheat sensitivity. World J Gastroenterol. 2015;21(23):7089-7109. doi:10.3748/wjg.v21.i23.7089

138. Choung RS, Murray JA. The role for food allergies in the pathogenesis of irritable bowel syndrome: understanding mechanisms of intestinal mucosal responses against food antigens. Gastroenterology. 2019;157 (1):15-17. doi:10.1053/j.gastro.2019.05.042 
139. Aguilera-Lizarraga J, Florens MV, Viola MF, et al. Boeckxstaens. Local immune response to food antigens drives meal-induced abdominal pain. Nature. 2021;590(7844):151-156. doi:10.1038/ s41586-020-03118-2

140. Pickert CN, Lorentz A, Manns MP, Bischoff SC. Colonoscopic allergen provocation test with $\mathrm{rBet} \mathrm{v} 1$ in patients with pollen-associated allergy. Allergy. 2012;67(10):1308-1315. doi:10.1111/all.12006

141. Bischoff SC, Mayer J, Meier PN, Zeck-Kapp G, Manns MP. Clinical significance of the colonoscopic allergen provocation test. Int Arch Allergy Immunol. 1997;113(1-3):348-351. doi: $10.1159 / 000237598$

142. Magnusson J, Lin XP, Dahlman-Höglund A, et al. Seasonal intestinal inflammation in patients with birch pollen allergy. $J$ Allergy Clin Immunol. 2003;112(1):45-50. doi:10.1067/ mai.2003.1604

143. Rentzos G, Lundberg V, Stotzer PO, Pullerits T, Telemo E. Intestinal allergic inflammation in birch pollen allergic patients $\mathrm{n}$ relation to pollen season, IgE sensitization profile and gastrointestinal symptoms. Clin Transl Allergy. 2014;4:19. doi:10.1186/ 2045-7022-4-19

144. Lee HS, Lee KJ. Alterations of food-specific serum IgG4 titers to common food antigens in patients with irritable bowel syndrome. J Neurogastroenterol Motil. 2017;23(4):578-584. doi:10.5056/ jnm17054

145. Guo H, Jiang T, Wang J, Chang Y, Guo H, Zhang W. The value of eliminating foods according to food-specific immunoglobin $\mathrm{G}$ antibodies in irritable bowel syndrome with diarrhoea. $J$ Int Med Res. 2012;40(1):204-210. doi:10.1177/147323001204000121

146. Zar S, Mincher L, Benson MJ, Kumar D. Food-specific IgG4 antibody-guided exclusion diet improves symptoms and rectal compliance in irritable bowel syndrome. Scand J Gastroenterol. 2005;40(7):800-807. doi:10.1080/00365520510015593

147. Kanagaratham C, El Ansari YS, Lewis OL, Oettgen HC. IgE and IgG antibodies as regulators of mast cell and basophil functions in food allergy. Front Immunol. 2020;11:603050. doi:10.3389/ fimmu.2020.603050

148. Schmiechen ZC, Weissler KA, Firschmeyer-Guerrerio PA. Recent developments in understanding mechanisms of food allergy. Curr Opin Pediatr. 2019;31(6):807-814. doi:10.1097/ MOP.0000000000000806

149. Atkinson W, Sheldon TA, Shaath N, Whorwell PJ. Food elimination based on $\operatorname{IgG}$ antibodies in irritable bowel syndrome: a randomized controlled trial. Gut. 2004;53(10):1459-1464. doi:10.1136/gut.2003.037697

150. Cappelletti M, Tognon E, Vona L, et al. Food-specific serum IgG and symptom reduction with a personalized, unrestricted-calorie diet of six weeks in irritable bowel syndrome (IBS). Nutr Metab (Lond). 2020;17(1):101. doi:10.1186/s12986-020-00528-x

151. Cozma-Petruţ A, Loghin F, Miere D, Dunitraşcu DL. Diet in irritable bowel syndrome: what to recommend, not what to forbid to patients! World J Gastroenterol. 2017;23(21):3771-3783. doi:10.3748/wjg.v23.i21.3771

152. Cristofori F, Dargenio VN, Dargenio C, Miniello VL, Barone M, Francavilla R. Anti-inflammatory and immunomodulatory effects of probiotics in gut inflammation: a door to the body. Front Immunol. 2021;12:578386. doi:10.3389/fimmu.2021.578386

153. Bauserman M, Michail S. The use of Lactobacillus GG in irritable bowel syndrome in children: a double-blind randomized control trial. $J$ Pediatr. 2005;147(2):197-201. doi:10.1016/j. jpeds.2005.05.015

154. Gawrońska A, Dziechciarz P, Horvath A, Szajewska H. A randomized double-blind placebo-controlled trial of Lactobacillus GG for abdominal pain disorders in children. Aliment Pharmacol Ther. 2007;25(2):177-184. doi:10.1111/ j.1365-2036.2006.03175.x
155. Guandalini S, Magazzù G, Chiaro A, et al. VSL\#3 improves symptoms in children with irritable bowel syndrome: a multicenter, randomized, placebo-controlled, double-blind, crossover study. J Pediatr Gastroenterol Nutr. 2010;51 (1):24-30. doi:10.1097/MPG.0b013e3181ca4d95

156. Romano C, Ferrau V, Cavataio F, et al. Lactobacillus reuteri in children with functional abdominal pain (FAP). $J$ Paediatr Child Health. 2014;50(10):E68-E71. doi:10.1111/j.1440-1754.2010.01797.x

157. Francavilla R, Miniello V, Magistà AM, et al. A randomized controlled trial of Lactobacillus GG in children with functional abdominal pain. Pediatrics. 2010;126(6):e1445-e1452. doi:10.1542/peds.2010-0467

158. Asgarashirazi M, Shariat M, Dalili $\mathrm{H}$. Comparison of the effects of $\mathrm{pH}-$ dependent peppermint oil and symbiotic lactol (Bacillus coagulans + fructooligosaccharides) on childhood functional abdominal pain: a randomized placebo-controlled study. Iran Red Crescent Med J. 2015;17(4):e23844. doi:10.5812/ircmj.17(4)2015.23844

159. Kianifar H, Jafari SA, Kiani M, et al. Probiotic for irritable bowel syndrome in pediatric patients: a randomized controlled clinical trial. Electron Physician. 2015;7(5):1255-1260.

160. Eftekhari K, Vahedi Z, Aghdam MK, Diaz DN. A randomized double-blind placebo-controlled trial of Lactobacillus reuteri for chronic functional abdominal pain in children. Iran J Pediatr. 2015;25(6):e2616. doi:10.5812/ijp.2616

161. Weizman Z, Abu-Abed J, Binsztok M. Lactobacillus reuteri DSM 17938 for the management of functional abdominal pain in childhood: a randomized, double-blind, placebo-controlled trial. J Pediatr. 2016;174:160-164.e1. doi:10.1016/j.jpeds.2016.04.003

162. Gianetti E, Maglione M, Alessandrella A, et al. A mixture of 3 Bifidobacteria decreases abdominal pain and improves quality of life in children with irritable bowel syndrome. A multicenter, randomized, double-blind, placebo-controlled, crossover trial. $J$ Clin Gastroenterol. 2017;51(1):e5-e10. doi:10.1097/ MCG.0000000000000528

163. Jadrešin O, Hojsak I, Mišak Z, et al. Lactobacillus reuteri DSM 17938 in the treatment of functional abdominal pain in children: RCT study. J Pediatr Gastroenterol Nutr. 2017;64(6):925-929. doi:10.1097/MPG.0000000000001478

164. Maragkoudaki M, Chouliaras G, Orel R, Horvath A, Szajewska H, Papadopoulou A. Lactobacillus reuteri DSM 17938 and a placebo both significantly reduced symptoms in children with functional abdominal pain. Acta Paediatr. 2017;106(11):1857-1862. doi:10.1111/apa.13992

165. Rahmani P, Ghouran-Orimi A, Motamed F, Moradzadeh A. Evaluating the effects of probiotics in pediatrics with recurrent abdominal pain. Clin Exp Pediatr. 2020;63(12):485-490. doi:10.3345/cep.2019.01613

166. Zernikow B, Wager J, Hechler T, et al. Characteristics of highly impaired children with severe chronic pain: a 5-year retrospective study on 2249 pediatric pain patients. BMC Pediatr. 2012;12:54. doi:10.1186/1471-2431-12-54

167. Schurman JV, Danda CE, Friesen CA, Hyman PE, Simon SD, Cocjin JT. Variations in psychological profile among children with recurrent abdominal pain. J Clin Psychol Med Settings. 2008;15:241-251. doi:10.1007/s10880-008-9120-0

168. Levy RL, Langer SL, Romano JM, et al. Cognitive mediators of treatment outcomes in pediatric functional abdominal pain. Clin $J \quad$ Pain. 2014;30(12):1033-1043. doi:10.1097/AJP.00000 00000000077

169. Bonnert M, Olén $\mathrm{O}$, Bjureberg $\mathrm{J}$, et al. the role of avoidance behavior in the treatment of adolescents with irritable bowel syndrome: a mediation analysis. Behav Res Ther. 2018;105:27-35. doi:10.1016/j.brat.2018.03.006

170. Reed B, Buzenski J, van Tilburg MAL. Implementing psychological therapies for gastrointestinal disorders in pediatrics. Expert Rev Gastroenterol Hepatol. 2020;14(11):1061-1067. doi:10.1080/ 17474124.2020.1806055 
171. Schurman JV, Friesen CA. Integrative treatment approaches: family satisfaction with a multidisciplinary paediatric abdominal pain clinic. Int J Integr Care. 2010;10:e51.

172. Keefer L, Palsson OS, Pandolfino JE. Best practice update: incorporating psychogastroenterology into management of digestive disorders. Gastroenterology. 2018;154(5):1249-1257. doi:10.1053/j.gastro.2018.01.045

173. Person H, Keefer L. Brain-gut therapies for pediatric functional gastrointestinal disorders and inflammatory bowel disease. Curr Gastroenterol Rep. 2019;21(4):12. doi:10.1007/s11894-019-0683-8

174. Levy RL, Langer SL, Walker LS. Cognitive-behavioral therapy for children with functional abdominal pain and their parents decreases pain and other symptoms. Am $J$ Gastroenterol. 2010;105(4):946-956. doi:10.1038/ajg.2010.106

175. Gro $\beta$ M, Warschburger P. Evaluation of a cognitive-behavioral pain management program for children with chronic abdominal pain: a randomized controlled study. Int J Behav Med. 2013;20 (3):434-443. doi:10.1007/s12529-012-9228-3

176. Levy RL, Langer SL, Walker LS. Twelve-month follow-up of cognitive behavioral therapy for children with functional abdominal pain. JAMA Pediatr. 2013;167(2):178-184. doi:10.1001/ 2013.jamapediatrics. 282

177. Sanders MR, Shepherd RW, Cleghorn G, Woolford H. The treatment of recurrent abdominal pain in children: a controlled comparison of cognitive-behavioral family intervention and standard pediatric care. J Consult Clin Psychol. 1994;62(2):306-314. doi:10.1037/0022-006X.62.2.306

178. Robins PM, Smith SM, Glutting JJ, Bishop CT. A randomized controlled trial of a cognitive-behavioral family intervention for pediatric recurrent abdominal pain. J Pediatr Psychol. 2005;30 (5):397-408. doi:10.1093/jpepsy/jsi063

179. van der Veek SMC, Derkx BHF, Benninga MA, Boer F, de Haan E. Cognitive behavior therapy for pediatric functional abdominal pain: a randomized controlled trial. Pediatrics. 2013;132(5):e1163-e1172. doi:10.1542/peds.2013-0242

180. Duarte MA, Penna FJ, Andrade EMG, Cancela CSP, Neto FCA, Barbosa TF. Treatment of nonorganic recurrent abdominal pain: cognitive-behavioral family intervention. J Pediatr Gastroenterol Nutr. 2006;43(1):59-64. doi:10.1097/01.mpg.0000226373.10871.76

181. Palermo TM, Wilson AC, Peters M, Lewandowski A, Somhegyi H. Randomized controlled trial of an internet-delivered family cognitive-behavioral therapy intervention for children and adolescents with chronic pain. Pain. 2009;146(1-2):205-213. doi:10.1016/j.pain.2009.07.034

182. Palermo TM, Law EF, Fales J, Bromberg MH, Jessen-Fiddick T, Tai G. Internet-delivered cognitive-behavioral treatment for adolescents with chronic pain and their parents: a randomized controlled multicenter trial. Pain. 2016;157(1):174-185. doi:10.1097/ j.pain.0000000000000348

183. Levy RL. Brief telephone-delivered cognitive behavioral therapy targeted to parents of children with functional abdominal pain: a randomized controlled trial. Pain. 2017;158(4):618-628. doi:10.1097/j.pain.0000000000000800

184. Lalouni M, Ljótsson B, Bonnert $\mathrm{M}$, et al. Internet-delivered cognitive behavioral therapy for children with pain-related functional gastrointestinal disorders: feasibility study. JMIR Ment Health. 2017;4(3):e32. doi:10.2196/mental.7985

185. Bonnert M, Olén O, Lalouni $\mathrm{M}$, et al. Internet-delivered exposure-based cognitive-behavioral therapy for adolescents with functional abdominal pain or functional dyspepsia: a feasibility study. Behav Ther. 2019;50(1):177-188. doi:10.1016/j.beth.2018.05.002

186. Lalouni M, Ljotsson B, Bonnert M. Clinical and cost effectiveness of online cognitive behavioral therapy in children with functional abdominal pain disorders. Clin Gastroenterol Hepatol. 2019;17(11):2236-2244.e11.
187. Bonnert M, Olén O, Lalouni M, et al. Internet-delivered cognitive behavior therapy for adolescents with irritable bowel syndrome: a randomized controlled trial. Am J Gastroenterol. 2017;112 (1):152-162. doi:10.1038/ajg.2016.503

188. Gulewitsch MD, Möller J, Hautzinger M, Schlarb AA. Brief hypnotherapeutic-behavioral intervention for functional abdominal pain and irritable bowel syndrome in childhood: a randomized controlled trial. Eur J Pediatr. 2013;172 (8):1043-1051. doi:10.1007/s00431-013-1990-y

189. Vlieger AM, Menko-Frankenhuis C, Woldkamp SCS, Tromp E, Benninga MA. Hypnotherapy for children with functional abdominal pain or irritable bowel syndrome: a randomized controlled trial. Gastroenterology. 2007;133(5):1430-1436. doi:10.1053/j. gastro.2007.08.072

190. Weydert JA, Shapiro DE, Acra SA, Monheim CJ, Chambers AS, Ball TM. Evaluation of guided imagery as treatment for recurrent abdominal pain in children: a randomized controlled trial. $B M C$ Pediatr. 2006;6:29. doi:10.1186/1471-2431-6-29

191. Rutten JMTM, Vlieger AM, Frankenhuis C. Home-based hypnotherapy self-exercises vs individual hypnotherapy with a therapist for treatment of pediatric irritable bowel syndrome, functional abdominal pain, or functional abdominal pain syndrome: a randomized clinical trial. JAMA Pediatr. 2017;171 (5):470-477.

192. van Tilburg MAL, Chitkara DK, Palsson OS, et al. Audiorecorded guided imagery treatment reduces functional abdominal pain in children: a pilot study. Pediatrics. 2009;124(5):e890 e897

193. Vlieger AM, Rutten JMTM, Govers AMAP, Frankenhuis C, Benninga MA. Long-term follow-up of gut-directed hypnotherapy vs. standard care in children with functional abdominal pain or irritable bowel syndrome. Am J Gastroenterol. 2012;107 (4):627-631. doi:10.1038/ajg.2011.487

194. Schurman JV, Wu YP, Grayson P, Friesen CA. A pilot study to assess the efficacy of biofeedback-assisted relaxation training as an adjunct treatment for pediatric functional dyspepsia associated with duodenal eosinophilia. $J$ Pediatr Psychol. 2010;35 (8):837-847. doi:10.1093/jpepsy/jsq010

195. Humphreys PA, Gervitz RN. Treatment of recurrent abdominal pain: components analysis of four treatment protocols. J Pediatr Gastroenterol Nutr. 2000;31(1):47-51. doi:10.1097/00005176200007000-00011

196. Shetty R, Kongasseri S, Rai S. Efficacy of mindfulness based cognitive therapy on children with anxiety. J Cogn Psychother. 2020;34(4):306-318. doi:10.1891/JCPSY-D-20-00014

197. Dunning DL, Griffiths K, Kuyken W, et al. Research review: the effects of mindfulness-based interventions on cognition and mental health in children and adolescents- a meta-analysis of randomized controlled trials. J Child Psychol Psychiatry. 2019;60 (3):244-258

198. Naliboff BD, Smith SR, Serpa JG, et al. Mindfulness-based stress reduction improves irritable bowel syndrome (IBS) symptoms via specific aspects of mindfulness. Neurogastroenterol Motil. 2020;32(9):e13828. doi:10.1111/nmo.13828

199. Aucoin M, Lalonde-Parsi MJ, Cooley K. Mindfulness-based therapies in the treatment of functional gastrointestinal disorders: a meta-analysis. Evid Based Complement Alternat Med. 2014;2014:140724. doi:10.1155/2014/140724

200. Ghandi F, Sadeghi A, Bakhtyari M, Imani S, Abdi S, Banihashem SS. Comparing the efficacy of mindfulness-based stress reduction therapy with emotion regulation treatment on quality of life and symptoms of irritable bowel syndrome. Iran J Psychiatry. 2018;13(3):175-183.

201. Benninga MA, Mayer EA. The power of placebo in pediatric functional gastrointestinal disease. Gastroenterology. 2009;137 (4):1207-1210. doi:10.1053/j.gastro.2009.08.023 
202. Hoekman DR, Zeevenhooven J, van Etten-jamaludin FS, et al. The placebo response in pediatric abdominal pain-related functional gastrointestinal disorders: a systematic review and meta-analysis. $J$ Pediatr. 2017;182(155-163.e7):155-163.e7. doi:10.1016/j.jpeds.2016.12.022

203. Talley NJ, Locke GR, Lahr BD, et al. Predictors of the placebo response in functional dyspepsia. Aliment Pharmacol Ther. 2006;23(7):923-936. doi:10.1111/j.1365-2036.2006.02845.x

204. Enck P, Klosterhalfen S. The placebo response in functional bowel disorders: perspectives and putative mechanisms. Neurogastroenterol Motil. 2005;17(3):325-331. doi:10.1111/ j.1365-2982.2005.00676.x

205. Kaptchuk TJ, Friedlander E, Kelley JM, et al. Placebos without deception: a randomized controlled trial in irritable bowel syndrome. PLoS One. 2010;5(12):e15591. doi:10.1371/journal.pone.0015591

206. Lembo A, Kelley JM, Nee J, et al. Open-label placebo vs double-blind placebo for irritable bowel syndrome: a randomized clinical trial. Pain. 2021;Publish Ahead of Print. doi:10.1097/j.pain.0000000000002234

207. Friesen CA, Schurman JV, Abdel-Rahman SM. Present state and future challenges in pediatric abdominal pain therapeutics research: looking beyond the forest. World $J$ Gastrointest Pharmacol Ther. 2015;6(4):96-104. doi:10.4292/wjgpt.v6.i4.96

208. Vandenberghe A, Schol J, Van den Houte K, Masuy I, Carbone F, Tack J. Current and emerging therapeutic options for the management of functional dyspepsia. Expert Opin Pharmacother. 2020;21(3):365-376. doi:10.1080/14656566.2019.1707805

209. Colomier E, Algera J, Melchior C. Pharmacological therapies and their clinical targets in irritable bowel syndrome with diarrhea. Front Pharmacol. 2021;11:629026. doi:10.3389/fphar.2020.629026

210. Karunanayake A, Devanarayana NM, de Silva A, Gunawardena S, Rajindrajith S. Randomized controlled trial on value of domperidone in functional abdominal pain in children. J Pediatr Gastroentrol Nutr. 2018;66(5):725-731. doi:10.1097/ MPG.0000000000001819

211. Collins BS, Lin HC. Double-blind, placebo-controlled antibiotic treatment study of small intestinal bacterial overgrowth in children with chronic abdominal pain. J Pediatr Gastroenterol Nutr. 2011;52(4):382-386. doi:10.1097/MPG.0b013e3181effa3b

212. Zybach K, Friesen CA, Schurman JV. Therapeutic effect of melatonin on pediatric functional dyspepsia: a pilot study. World $J$ Gastrointest Pharmacol Ther. 2016;7(1):156-161. doi:10.4292/wjgpt.v7.i1.156

213. Badihian N, Yaghini O, Badihian S, Shahsanai A, Saneian H. Comparison of the efficacy of buspirone and placebo in childhood functional abdominal pain: a randomized clinical trial. $\mathrm{Am}$ $J \quad$ Gastroenterol. 2020;115(5):756-765. doi:10.14309/ ajg.0000000000000589

214. Sadeghian M, Farahmand F, Fallahi GH, Abbasi A. Cyproheptadine for the treatment of functional abdominal pain in childhood: a double-blinded randomized placebo-controlled trial. Minerva Pediatr. 2008;60(6):1367-1374.

215. See MC, Birnbaum AH, Schechter CB, Goldenberg MM, Benkov KJ. Double-blind, placebo-controlled trial of famotidine in children with abdominal pain and dyspepsia: global and quantitative assessment. Dig Dis Sci. 2001;46(5):985-992. doi:10.1023/A:1010793408132

216. Kline RM, Kline JJ, Di Palma J, Barbero GJ. Enteric-coated, $\mathrm{pH}$-dependent peppermint oil capsules for the treatment of irritable bowel syndrome in children. $J$ Pediatr. 2001;138(1):125-128. doi:10.1067/mpd.2001.109606

217. Friesen CA, Kearns GL, Andre L, Neustrom M, Roberts CC, Abdel-Rahman SM. Clinical efficacy and pharmacokinetics of montelukast in dyspeptic children with duodenal eosinophilia. $J$ Pediatr Gastroenterol Hepatol. 2004;38(3):343-351. doi:10.1097/00005176-200403000-00021
218. Narang M, Shah D, Akhtar H. Efficacy and safety of drotaverine hydrochloride in children with recurrent abdominal pain: a randomized placebo controlled trial. Indian Pediatr. 2015;52 (10):847-851. doi:10.1007/s13312-015-0730-y

219. Symon DNK, Russell G. Double blind placebo controlled trial of pizotifen syrup in the treatment of abdominal migraine. Arch Dis Child. 1995;72(1):48-50. doi:10.1136/adc.72.1.48

220. Pourmoghaddas Z, Saneian H, Roohafza H, Gholamrezaei A. Mebeverine for pediatric functional abdominal pain: a randomized, placebo-controlled trial. Biomed Res Int. 2014;2014:191026. doi:10.1155/2014/191026

221. Saps M, Youssef N, Miranda A, et al. Multicenter, randomized, placebo-controlled trial fo amitriptyline in children with functional gastrointestinal disorders. Gastroenterology. 2009;137 (4):1261-1269. doi:10.1053/j.gastro.2009.06.060

222. Bahar RJ, Collins BS, Steinmetz B, Ament ME. Double-blind placebo-controlled trial of amitriptyline for the treatment of irritable bowel syndrome in adolescents. J Pediatr. 2008;152 (5):685-689. doi:10.1016/j.jpeds.2007.10.012

223. Roohafza H, Pourmoghaddas Z, Saneian H, Gholamrezaei A. Citalopram for pediatric functional abdominal pain: a randomized, placebo-controlled trial. Neurogastroenterol Motil. 2014;26(11):1642-1650.

224. Dehghani SM, Imanieh MH, Oboodi R, Haghighat M. The comparative study of the effectiveness of cimetidine, ranitidine, famotidine, and omeprazole in treatment of children with dyspepsia. ISRN Pediatr. 2011;2011:219287. doi:10.5402/2011/ 219287

225. Rodriguez L, Diaz J, Nurko S. Safety and efficacy of cyproheptadine for treating dyspeptic symptoms in children. $J$ Pediatr. 2013;163(1):261-267. doi:10.1016/j.jpeds.2012.12.096

226. Madani S, Cortes O, Thomas R. Cyproheptadine use in children with functional gastrointestinal disorders. $J$ Pediatr Gastroenterol Nutr. 2016;62(3):409-413. doi:10.1097/ MPG.0000000000000964

227. Tack J, Janssen P, Masaoka T, Farré R, Van Oudenhove L. Efficacy of buspirone, a fundus-relaxing drug, in patients with functional dyspepsia. Clin Gastroenterol Nutr. 2012;10 (11):1239-1245. doi:10.1016/j.cgh.2012.06.036

228. Braak B, Klooker TK, Wouters MM, Lei A, van den Wijngaard RM, Boeckxstaens GE. Randomized clinical trial: the effects of amitriptyline on drinking capacity and symptoms in patients with functional dyspepsia, a double-blind placebo-controlled study. Aliment Pharmacol Ther. 2011;34 (6):638-648. doi:10.1111/j.1365-2036.2011.04775.x

229. Chogle A, Saps M. Electrocardiograms changes in children with functional gastrointestinal disorders on low dose amitriptyline. World J Gastroenterol. 2014;20(32):11321-11325. doi:10.3748/ wjg.v20.i32.11321

230. Patra KP, Sankararaman S, Jackson R, Hussain SZ. Significance of screening electrocardiogram before the initiation of amitriptyline therapy in children with functional abdominal pain. Clin Pediatr (Phila). 2012;51(9):848-851. doi:10.1177/0009922812447890

231. Khoshoo V, Armstead C, Landry L. Effect of a laxative with and without tegaserod in adolescents with constipation predominant irritable bowel syndrome. Aliment Pharmacol Ther. 2006;23 (1):191-196. doi:10.1111/j.1365-2036.2006.02705.x

232. Niesler B, Kuerten S, Demir IE, Schäfer KH. Disorders of the enteric nervous system- a holistic view. Nat Rev Gastroenterol Hepatol. 2021. doi:10.1038/s41575-020-00385-2

233. Kovacic K, Hainsworth K, Sood M, et al. Neurostimulation for abdominal pain-related functional gastrointestinal disorders in adolescents: a randomized, double-blind, sham-controlled trial. Lancet Gastroenterol Hepatol. 2017;2(10):727-737. doi:10.1016/S24681253(17)30253-4 
234. Kaniusas E, Kampusch S, Tittgemeyer M, et al. Current directions in the auricular vagus nerve stimulation I- A physiologic perspective. Front Neurosci. 2019;13:854. doi:10.3389/fnins.2019.00854

235. Zhu Y, Xu F, Lu D, et al. Transcutaneous auricular vagal nerve stimulation improves functional dyspepsia by enhancing vagal efferent activity. Am J Physiol Gastrointest Liver Physiol. 2021;320(5):G700-G711. doi:10.1152/ajpgi.00426.2020
236. Krasaelap A, Sood MR, Li BUK, et al. Efficacy of auricular neurostimulation in adolescents with irritable bowel syndrome in a randomized, double-blind trial. Clin Gastroenterol Hepatol. 2020;18(9):1987-1994.e2. doi:10.1016/j.cgh.2019.10.012

\section{Publish your work in this journal}

Pediatric Health, Medicine and Therapeutics is an international, peerreviewed, open access journal publishing original research, reports, editorials, reviews and commentaries. All aspects of health maintenance, preventative measures and disease treatment interventions are addressed within the journal. Practitioners from all disciplines are invited to submit their work as well as healthcare researchers and patient support groups. The manuscript management system is completely online and includes a very quick and fair peer-review system. Visit http://www.dovepress.com/testimonials.php to read real quotes from published authors. 